\title{
Cochrane
}

Library

Cochrane Database of Systematic Reviews

\section{Effectiveness of intermediate care in nursing-led in-patient units} (Review)

Griffiths PD, Edwards ME, Forbes A, Harris RG, Ritchie G

Griffiths PD, Edwards ME, Forbes A, Harris RG, Ritchie G.

Effectiveness of intermediate care in nursing-led in-patient units.

Cochrane Database of Systematic Reviews 2007, Issue 2. Art. No.: CD002214.

DOI: 10.1002/14651858.CD002214.pub3.

www.cochranelibrary.com 
TABLE OF CONTENTS

HEADER

ABSTRACT

PLAIN LANGUAGE SUMMARY

BACKGROUND

OBJECTIVES

METHODS

RESULTS

DISCUSSION

AUTHORS' CONCLUSIONS

ACKNOWLEDGEMENTS

REFERENCES

CHARACTERISTICS OF STUDIES

DATA AND ANALYSES

Analysis 1.1. Comparison 1 NLU vs general inpatient care, Outcome 1 Inpatient mortality.

Analysis 1.2. Comparison 1 NLU vs general inpatient care, Outcome 2 Early post discharge death (4-6 weeks).

Analysis 1.3. Comparison $1 \mathrm{NLU}$ vs general inpatient care, Outcome 3 Mortality within 3 months of admission (12 weeks / 90 days).

Analysis 1.4. Comparison $1 \mathrm{NLU}$ vs general inpatient care, Outcome 4 Mortality within 6 months of admission (24 weeks / 180 days).

Analysis 1.5. Comparison 1 NLU vs general inpatient care, Outcome 5 Mortality to longest follow up (within 6 months). ..........

Analysis 1.6. Comparison $1 \mathrm{NLU}$ vs general inpatient care, Outcome 6 Discharge to institutional care.

Analysis 1.7. Comparison 1 NLU vs general inpatient care, Outcome 7 Independent at discharge.

Analysis 1.8. Comparison $1 \mathrm{NLU}$ vs general inpatient care, Outcome 8 Institutional care to longest follow up.

Analysis 1.9. Comparison $1 \mathrm{NLU}$ vs general inpatient care, Outcome 9 Functional Status.

Analysis 1.10. Comparison 1 NLU vs general inpatient care, Outcome 10 Change in functional Status (admission to discharge). .

Analysis 1.11. Comparison 1 NLU vs general inpatient care, Outcome 11 Length of stay to first discharge from hospital setting. .

Analysis 1.12. Comparison $1 \mathrm{NLU}$ vs general inpatient care, Outcome 12 Length of stay to first discharge home.

Analysis 1.13. Comparison 1 NLU vs general inpatient care, Outcome 13 Early readmission (within 30 days). .........................

Analysis 1.14. Comparison $1 \mathrm{NLU}$ vs general inpatient care, Outcome 14 Quality of life / health status.

Analysis 1.15. Comparison 1 NLU vs general inpatient care, Outcome 15 Quality of life / health status change scores only. ......

Analysis 1.16. Comparison $1 \mathrm{NLU}$ vs general inpatient care, Outcome 16 Psychological wellbeing.

Analysis 1.17. Comparison 1 NLU vs general inpatient care, Outcome 17 Satisfaction.

Analysis 2.1. Comparison $2 \mathrm{NLU}$ vs ICU, Outcome 1 Inpatient mortality.

Analysis 2.2. Comparison 2 NLU vs ICU, Outcome 2 Mortality to longest follow up (Up to 24 months).

Analysis 2.3. Comparison 2 NLU vs ICU, Outcome 3 Discharge to institutional care.

Analysis 2.4. Comparison $2 \mathrm{NLU}$ vs ICU, Outcome 4 Length of stay to first discharge home.

Analysis 2.5. Comparison $2 \mathrm{NLU}$ vs ICU, Outcome 5 Early readmission (within 30 days).

ADDITIONAL TABLES

WHAT'S NEW

HISTORY

CONTRIBUTIONS OF AUTHORS

DECLARATIONS OF INTEREST

SOURCES OF SUPPORT

INDEX TERMS 
[Intervention Review]

\section{Effectiveness of intermediate care in nursing-led in-patient units}

Peter D Griffiths ${ }^{1}$, Margaret E Edwards², Angus Forbes², Ruth G Harris ${ }^{3}$, Gill Ritchie 4

1School of Nursing and Midwifery, King's College London, London, UK. 2Florence Nightingale School of Nursing and Midwifery, King's College London, London, UK. 3Faculty of Health and Social Care Sciences, Kingston University and St George's University of London, London, UK. ${ }^{4}$ National Collaborating Centre for Primary Care, London, UK

Contact address: Peter D Griffiths, School of Nursing and Midwifery, King's College London, Room 3.29b JCMB, Waterloo Road, London, SE1 8WA, UK. peter.griffiths@kcl.ac.uk.

Editorial group: Cochrane Effective Practice and Organisation of Care Group

Publication status and date: Edited (no change to conclusions), published in Issue 1, 2009.

Citation: Griffiths PD, Edwards ME, Forbes A, Harris RG, Ritchie G. Effectiveness of intermediate care in nursing-led in-patient units. Cochrane Database of Systematic Reviews 2007, Issue 2. Art. No.: CD002214. DOI: 10.1002/14651858.CD002214.pub3.

Copyright @ 2009 The Cochrane Collaboration. Published by John Wiley \& Sons, Ltd.

\section{A B S T R A C T}

\section{Background}

The Nursing led inpatient Unit (NLU) is one of a range of services that have been considered in order to manage more successfully the transition between hospital and home for patients with extended recovery times. This is an update of an earlier review published in The Cochrane Library in Issue 3, 2004.

\section{Objectives}

To determine whether nursing-led inpatient units are effective in preparing patients for discharge from hospital compared to usual inpatient care.

\section{Search methods}

We searched The Cochrane Library, the Specialized Register of the Cochrane Effective Practice and Organisation of Care (EPOC) group, MEDLINE, CINAHL, EMBASE, BNI and HMIC databases. Citation searches were undertaken on the science and social science citation indices. Authors were contacted to identify additional data. The initial search was done in January 2001. The register search was updated in October 2006, the other database searches were updated in November 2006 and the citation search was run in January 2007.

\section{Selection criteria}

Controlled trials and interrupted time series designs that compared the NLU to usual inpatient care managed by doctors. Patients over 18 years of age following an acute hospital admission for a physical health condition.

\section{Data collection and analysis}

Two reviewers independently extracted data and assessed study quality.

\section{Main results}

Ten random or quasi-random controlled trials reported on a total of 1896 patients. There was no statistically significant effect on inpatient mortality (OR 1.10, 95\% Cl 0.56 to 2.16 ) or mortality to longest follow up (OR $0.92,95 \% \mathrm{Cl} 0.65$ to 1.29 ) but higher quality studies showed a larger non-significant increase in inpatient mortality (OR 1.52, 95\% $\mathrm{Cl} 0.86$ to 2.68 ). Discharge to institutional care was reduced for the NLU (OR $0.4495 \% \mathrm{Cl} 0.22$ to 0.89 ) and functional status at discharge increased (SMD $0.37,95 \% \mathrm{Cl} 0.20$ to 0.54 ) but there was a near significant increase in inpatient stay (WMD 5.13 days $95 \% \mathrm{Cl}-0.5$ days to 10.76 days). Early readmissions were reduced $(\mathrm{OR} 0.5295 \% \mathrm{Cl} 0.34$ to 0.80$)$. One study compared a NLU for the chronically critically ill with ICU care. Mortality (OR $0.6295 \% \mathrm{Cl} 0.35$ to 1.10 ) and length of inpatient stay differ did not differ (WMD 2 days, $95 \% \mathrm{Cl} 10.96$ to -6.96 days). Early readmissions were reduced (OR $0.3395 \% \mathrm{Cl} 0.12$ to 0.94 ). Costs of care on the NLU were higher for UK studies but lower for US based studies. 


\section{Authors' conclusions}

There is some evidence that patients discharged from a NLU are better prepared for discharge but it is unclear if this is simply a product of an increased length of inpatient stay. No statistically significant adverse effects were noted but the possibility of increased early mortality cannot be discounted. More research is needed.

\section{PLAIN LANGUAGE SUMMARY}

\section{Effectiveness of intermediate care in nursing-led in-patient units}

Patients who suffer an acute illness and are admitted to hospital are often admitted into an acute care ward with many services provided. But while recovering from the illness they may not need those intense services and will need to prepare to go home. Nursing led inpatient units, which are managed by nurses as opposed to physicians, have been designed to prepare patients for home. Ten studies, including over 1800 patients, were analysed to determine if patients sent to a nursing led inpatient unit benefited or at least fared no worse than patients in a unit providing usual care. Compared to usual care, patients in nursing led inpatients units functioned better and experienced greater well-being; more patients were discharged home and not to an institution after about 3 months (but not after 6 months); fewer were readmitted back into hospital soon after discharge; but they stayed in hospital longer. The number of deaths during stay in hospital and 3 to 6 months after discharge was similar between the units (but there was a trend for more deaths early while in nursing led inpatients units that needs to be researched further). It is still not known whether nursing led inpatient units save money - studies in the United Kingdom found them more expensive than usual care units but studies in the United States found them cheaper. 


\section{B A C K G R O U N D}

There has been growing interest in alternatives to acute hospital care for patients who have passed the acute phases of illness. In the UK such services have been termed 'intermediate' care. They are broadly defined as '...that range of services designed to facilitate the transition from hospital to home, and from medical dependence to functional independence, where the objective of care is not primarily medical, the patient's discharge destination is anticipated and a clinical outcome of recovery (or restoration of health) is desired' (Steiner 1997). The development of intermediate care services aimed predominantly at older people formed a significant part of the UK Department of Health's plan for developing services for older people (DoH 2001). In the USA the need for services bridging the gap between acute services and home care or long term care has long been discussed in the face of measures designed to contain acute care costs for an ageing population (Bowcutt 2000). Similar developments are under consideration in much of the developed world.

The aim of intermediate care is two fold. Firstly, it is intended to enhance the quality of care received by patients while reducing or preventing an unnecessary acute hospital stay. Secondly, by removing these patients from acute care facilities, resources in those facilities can be used more appropriately. The potential need for intermediate care has been identified through numerous studies identifying large numbers of patients inappropriately placed in acute beds (Goddard 2000). These patients are said to neither require nor benefit from the full range of disciplines and facilities of the acute ward. However, there is a need to evaluate the effectiveness of any alternative provision in order to determine that it does indeed meet patient need to at least the level currently offered by acute services.

Alternatives to acute hospital care include interventions in the patient's own home, such as hospital-at-home (Knowelden 1991) and enhanced post-discharge support schemes (Martin 1991). A range of inpatient services have also been defined as intermediate care, including nursing led in-patient units (Pearson 1992), general practitioner run community hospitals (McCormack 1992) intermediate care in nursing homes (Ward 2003) and community care centres (Wilce 1988). Some sub-acute care centres in the USA also appear to be offering clinical services that fall within this spectrum (Griffiths 1997) as do some transitional care services and units focussing on care of the so called chronically critically ill (Daly 1995). Other services to which the term intermediate care have been applied in the USA do not fall within this spectrum as they provide either low intensity long term care or provide care that is primarily intermediate between critical care and general acute care units. The evidence base is weak. A review of the use of care home environments for the rehabilitation of older people (Ward 2003) found no evidence of high enough quality to include in their review. Hospital at home and other early discharge schemes are reviewed elsewhere (Shepperd 2005, Shepperd 2004). Evidence of benefit to patients of these interventions is weak although it seems that hospital at home can substitute for acute care.

This review will examine evidence for the effectiveness of inpatient intermediate care that substitutes for a period of acute hospital stay, specifically those models of care where nurses have replaced the care management function of hospital doctors and nursing is identified as the lead therapy. This model of care has been labelled in a variety of ways but is referred to here as a nursing-led inpatient unit (NLU). The potential effectiveness of this intervention is based on a hypothesised trajectory of care needs where (for some patients suffering some conditions) the main need during the predischarge period is nursing (Hall 1969). Transfer to a NLU is said to improve outcomes through the higher priority that can be given to professional nursing care for these sub-acute/rehabilitation patients in an environment where the needs of acute and non-acute patients do not compete (Griffiths 2000).

The intervention is multifaceted. The defining elements of the intervention are the professional substitution (nurse for doctor) and altered case mix of the unit. The aim is to enhance the quality and quantity of nursing care received by patients in preparation for discharge. The intervention is not simply discharge planning, although this may form an intrinsic part of the care package. Organisational changes in nursing care (such as primary nursing) and management (such as shared governance) have been associated with NLUs with the aim of improving the quality of nursing care. Although the nurse acts as care manager in the NLU this is as a substitute for medical management of care. This subject of this review thus differs from case management as an intervention, where the aim is to improve care through improved co-ordination, communication and inter-professional collaboration. The professional discipline of the case manager is irrelevant to this function. Other groups are currently reviewing case management (Zwarenstein 2000).

\section{OB JECTIVES}

The review aims to determine whether nursing-led inpatient units are effective in preparing patients for discharge from hospital. Effectiveness of the NLU will be compared to 'usual care' (inpatient care in general acute hospital wards). In order to achieve this, the objectives of the review are as follows:

(1) to identify patient outcomes for the NLU compared to usual care;

(2) to identify resource use/cost of the NLU compared to usual care.

The NLU would be deemed effective as a substitute for usual care if it achieved equal or improved outcomes.

\section{METHO D S}

\section{Criteria for considering studies for this review}

\section{Types of studies}

Randomised controlled trials (RCT) controlled clinical trials (CCT), controlled before and after trials (CBA) and interrupted time series designs.

\section{Types of participants}

Participants considered for inclusion in the review were adult patients who were assessed as eligible for nurse-managed care in a NLU where acute hospital (medically led) care is the alternative. Patients must be over 18 . The NLU care must have substituted for some or all of the acute hospital stay (i.e. not simply be an addition to usual inpatient care). Nurse-managed care that substitutes only for a stay in a mental health facility was not considered. No restrictions were made in terms of patient diagnoses. 


\section{Types of interventions}

Interventions must have been delivered in a setting other than the patients' home (hence 'institutional') including hospital wards, cottage hospitals and nursing homes. The nurse must have been the identified leader of the clinical team for a majority of patients in the unit. Where leadership is unclear, nurses having the authority to admit and discharge patients operationally defined nursemanagement of care. Services where nursing did not explicitly comprise the predominant therapy were included but considered separately. The aim of the intervention was crucial in identifying relevant studies. Although essentially subjective, the definition of intermediate care given above was used as the basis for inclusion. The intervention must have substituted for a period of inpatient care in an acute care facility where usual modes of care organisation were utilised. Specifically, the NLU must have been compared to inpatient care that was managed by a consultant (attending) physician or surgeon.

\section{Types of outcome measures}

The following outcome measures were considered for this review: mortality.

discharge to institutional care

independence / functional status

length of inpatient stay

readmission

measures of health status and psychological wellbeing

Measures of satisfaction

cost of inpatient care, and cost of post discharge care

\section{Search methods for identification of studies}

Initial searching for the review was conducted in January 2001 using the

following strategy on MEDLINE CINAHL and the Cochrane Library:

nurs\$ adj2 led

nurs $\$$ adj2 managed

nurs $\$$ adj2 directed

nursing adj bed

intermediate care

nurse clinicians (MeSH)

Clinical nurse specialist (key word and $\mathrm{MeSH}$ )

skilled nursing facilities (MeSH)

intermediate care facilities(MeSH)

sub-acute/sub acute care (key word and MeSH).

Searches were limited by using the methodological components of the EPOC

search strategy:

1. randomized controlled trial.pt.

2. controlled clinical trial.pt.

3. intervention studies/

4. experiment\$.tw.

5. (time adj series).tw.

6. (pre test or pretest or posttest or post test).tw.

7. random allocation/

8. impact.tw.

9. intervention?.tw.

10. chang\$.tw.

11. evaluation studies/
12. evaluat\$.tw.

13. effect?.tw.

14. comparative studies/

15. animal/

16. human/

17. 15 not 16

18. or/1-14

19. 18 not 17

(operators given are for OVID nearest equivalent operator used on other

interfaces).

Key word (free text only) versions of this strategy were conducted on

EMBASE, HMIC and BNI with synonymous index terms (where available)

identified using the OVID mapping function. Searches on BNI and HMIC

were not limited by method. The science and social science citation indices (ISI Web of Knowledge) were searched for citations to works of

key authors identified early in the search (Hall 1969, Hall 1975,

Pearson 1988a, Pearson 1988b, Pearson 1992, Evans 1994, Griffiths 1995,

Griffiths 1998).

Based on this broad strategy relevant citations were scrutinised and

more specific subject search strategy was devised.

(nurs\$ adj2 led or nurs\$ adj2 managed or nurs\$ adj2 directed) AND (intermediate care or nursing homes (MESH) or intermediate care facilities(MeSH) or sub-acute/sub acute care (key word and MeSH). This

was last run in November 2006.

The search was updated using the EPOC specialised register (See SPECIALISED REGISTER under GROUP DETAILS) and through contact with

experts in the field. The register was last searched in October 2006 using the relevant terms from the EPOC taxonomy. As additional papers

were identified for inclusion in the review these have been added to citation searches. The last citation search was performed in January

2007 to search for citations to all studies identified as included in this review.

\section{Data collection and analysis}

A single reviewer (PG) scanned the results from all searches to identify items in need of further scrutiny. Potentially relevant papers were retrieved. PG and one other reviewer independently read these publications. Those that described a clinical service that might meet the criteria and described any evaluation were retained for detailed consideration according to the criteria for patient and service type described above and the standard methodological criteria for inclusion in an EPOC review.

Data extraction was completed independently by pairs of reviewers using a checklist developed by EPOC, modified and amended for the purposes of this review (see METHODS USED IN REVIEWS under GROUP DETAILS). PG contacted investigators for further 
information where necessary. Where one of the reviewers was the author of a paper under consideration, reviewers who were not authors made decisions about inclusion. An author and a second reviewer who was not an author conducted data extraction from those studies. In all cases, disagreements were resolved by discussion. Of 23 studies that were identified for detailed scrutiny against the criteria, agreement on eligibility for inclusion was reached based on initial independent judgements in $21 / 23$ cases (kappa 0.83).

The quality of eligible trials was assessed using the criteria described by the EPOC group (see ADDITIONAL INFORMATION, ASSESSMENT OF METHODOLOGICAL QUALITY under GROUP DETAILS). A quality score was derived from the EPOC checklist based the number of quality criteria that were rated as done. There are seven criteria for RCTs and CCTs, although one of these (follow up of professionals) did not apply to studies where the unit of allocation and analysis was patients. In addition to the EPOC criteria, intention to treat analysis was recorded since selective attrition from the nurse-led group due to medical instability is a major potential source of bias in controlled trials in this area. This criterion was rated as done where authors clearly stated that they used an intention to treat analysis or sufficient description was given to determine that those allocated to the NLU were not dropped from the study if they became unwell. The criterion for adequate follow up was considered for length of stay and place of discharge or mortality as primary outcomes for the overall quality assessment. Where follow up for other outcomes fell below the acceptable level of $80 \%$ this is noted in the report of that outcome below. Of the outcomes considered, most were either patient completed (satisfaction, health status measures) or regarded as intrinsically objective (length of stay, mortality) and so overall consideration of blinding and reliability of outcome assessment was restricted to the assessment of functional status / dependence or other subjectively assessed outcomes.

Where services showed a degree of similarity in terms of setting and client group meta-analysis was performed. A random effect model was used. All analyses were sub divided according to the quality scores in order to allow an exploration of bias due to poor study quality. Studies meeting four or more quality criteria were rated as stronger, those meeting three or less were rated as weaker.

\section{RES U L T S}

\section{Description of studies}

See: tables of studies

The initial search identified approximately 10,000 unique citations. From these searches and subsequent updates, 234 papers appeared potentially relevant. These were screened on the basis of title and PG and AF retrieved abstract and the full text of 74 papers for further assessment. From these, 23 unique studies were identified as requiring detailed assessment. Seven studies were excluded as they as described interventions that did not meet the criteria specified for a nursing-led inpatient unit in intermediate care either because nurses did not lead the clinical team or the intervention was exclusively concerned with long term care. One failed to meet the criteria as nurses could admit to only two beds of a 17-bedded unit. Four papers provided descriptions of services but no evaluation or evaluations that failed the basic EPOC criteria (see table of excluded studies).
Eleven studies met all the review criteria. Of these 10 were RCTs (Pearson 1988a, Pearson 1988b, Griffiths 1995, Walsh 1999, Bowcutt 2000, Griffiths 2000, Griffiths 2001, Steiner 2001) or quasi-random CCTs (Hall 1975, Daly 1995) trials and one a CBA - (Davies 1994) (See table of included studies). Three of the RCTs used randomised consent designs (Zelen's design) with either double consent (to research participation and either allocated treatment Griffiths 1995, Griffiths 2000) or single consent - (to transfer to NLU only Steiner 2001). Sample sizes of the random / quasi-random studies were generally modest with the largest study having a sample of 539 (Hall 1975). In total 1896 patients were involved in the 10 trials. The CBA (Davies 1994) reported averages over periods before and after the NLU was established but did not identify the sample sizes.

Of the included studies, eight were conducted in the UK. Of these, three (Griffiths 1995, Walsh 1999, Steiner 2001) recruited patients following an acute general medical admission and three (Davies 1994, Griffiths 2000, Griffiths 2001) recruited patients post acute medical and general surgical admissions. In all cases, patients who had been admitted with a wide range of medical / surgical problems were treated. Two studies recruited patients with specific conditions (Hip fracture Pearson 1998a, hip fracture, stroke and amputation Pearson 1988b). Only Pearson 1988a and Davies 1994 had age specific admission policies (60+ and $75+$ respectively) but in all cases where detail is given the mean age of the patient population was over 70 years. All of these described a service for patients following acute admission and explicitly or implicitly described a recovery trajectory from medical to nursing need as part of their rationale. All offered a service that could broadly be described as non-specialist rehabilitation in a nurse-managed environment and placed emphasis on the therapeutic activity of nursing. Despite the heterogeneity of the original reason for hospital admission, these services have a number of features in common and selected patients based on non-medical need.

The remaining studies were conducted in the USA (Hall 1975, Daly 1995, Bowcutt 2000). Both Hall 1975, and Bowcutt 2000 describe services for patients from acute medical / surgical units although Hall 1975 studied only patients post cardiac event or surgery. Daly 1995 describes a service for patients who would otherwise experience an extended stay in ICU (the so called chronically critically ill). Since the majority of patients in the Nurse-led unit were discharged directly from the hospital it is included here as meeting the criteria for intermediate care although clearly to a very different clinical population. Both Hall 1975 and Daly 1995 explicitly identify nursing as therapy and identify rehabilitative goals of care. Bowcutt's description is less explicit although the intervention is designed to provide care in a more therapeutic environment with a holistic care approach. Only Bowcutt 2000 describes an age-limited service with a lower limit of 50 but all three cared for primarily elder patients with a mean age from 64 (Daly 1995) to 73 (Bowcutt 2000).

Some control group patients experiencing usual care were transferred from acute care to traditional rehabilitation or community hospital settings in most studies. In general, such facilities were not utilised as part of the transition for patients from the NLU. For the purpose of fair comparison, wherever possible the index admission is determined from entry into the study (or admission to hospital) until the patient has made the transition to their intended permanent place of residence (be it home or institution). Exceptions to this are noted in reporting of results. In 
all cases, the majority of patients spent the majority of their stay in either the NLU or acute units.

Specific detail of care provided to both intervention and usual care groups was lacking in many studies. In addition to those elements that define the intervention (nurse versus doctor leadership of care), care on the NLU was generally described as more patient centred with systems of nursing work such as primary nursing utilised. Descriptions of the NLU also typically described attempts to make the environment and living experience of the patients more homely and therapeutic (Pearson 1988a, Pearson 1988b, Daly 1995, Griffiths 1995, Griffiths 2000, Bowcutt 2000, Griffiths 2001) although the mechanisms for achieving this varied considerably. Where comparison was possible, the NLU generally offered enhanced skill mix in the nursing team with higher numbers of senior and specialist nurses than in control wards (Griffiths 2000, Griffiths 2001). Other studies described the presence of senior nurses and nurse specialists on the NLU but made no specific mention of their availability on control wards (Hall 1975, Pearson 1988a, Pearson 1988b, Daly 1995, Bowcutt 2000). Overall nurse staffing in NLU (including qualified and unqualified staff) was at an equivalent level to control conditions (Griffiths 1995, Griffiths 2000, Griffiths 2001, Steiner 2001) although in some cases the increased number of senior nurses was matched by a reduced number of qualified staff delivering patient care (Daly 1995, Griffiths 2000).

The updated search identified one study (Michael 2004), which was not a CBA and was excluded from the review.

\section{Risk of bias in included studies}

See table of included studies, Table 1 for summary of study validity.

The quality of studies was variable. See Table 1 for summary of quality assessment. Only three trials used concealed allocation (Pearson 1988a; Pearson 1988b, Griffiths 2001) although three others used randomised consent designs in which allocations cannot be concealed (Griffiths 1995, Griffiths 2000, Steiner 2001). Follow up of patients recruited into the trials was generally acceptable (10/11) although it was impossible to determine for one study. Length of stay (11/11) and discharge destination (10/11) which are not subject to interpretative bias were reported in most trials. No trial demonstrated blinded assessment of subjective outcomes such as functional status. Only $4 / 11$ clearly demonstrated that there were no important baseline differences between groups and for $4 / 11$ there were baseline differences that could favour the intervention (NLU) group. Only $3 / 11$ studies reported reliable assessment of subjective outcomes such as dependence. Most trials were well protected against contamination (9/11), since the intervention was unit based and control patients did not access the NLU. Re-admission of control patients to the NLU during the follow up occurred in one study although it is unlikely to have made a major impact on outcome as numbers were low. The potential for contamination in the CBA of Davies 1994 could not be assessed. Five trials explicitly used intention to treat analysis although it is only apparent that patients who became ill were selectively dropped from the intervention group in one case (Pearson 1988b) although the numbers so treated were low (2/84 patients).

Five studies were rated as stronger based on meeting 4 or more quality criteria. Five were rated as weaker based on meeting less than 4 criteria. One (Davies 1994) trial met none of the quality criteria specified for the relevant design (CBA). This study ultimately yielded no useable data for the review. Daly 1995 was deemed unsuitable for use in a any pooled analysis since the clinical service and client group was so clearly distinct from that offered by other NLUs.

\section{Effects of interventions}

Comparison 1: NLU vs. general inpatient care.

\section{Outcome: Mortality}

Seven studies reported inpatient mortality. Six studies reported mortality over extended periods. Griffiths 2000 reported up to 90 days post admission. Hall 1975, Griffiths 2001, Steiner 2001 reported six months post admission follow up and Pearson 1988a, Pearson 1988b reported six month post discharge follow up.

Meta-analysis shows no statistically significant difference in inpatient mortality between NLU and usual inpatient care (Odds Ration (OR) 1.10, 95\% Confidence Interval (CI) 0.56 to 2.16). One study (Pearson 1988b) showed a statistically significant reduction in mortality for the NLU (OR $0.395 \% \mathrm{Cl} 0.11$ to 0.81 ) although this could be accounted for by pre-test differences between groups. There was no difference in mortality to longest follow up (OR 0.92, 95\% Cl 0.65 to 1.29 ) and no individual study showed a significant difference. Analysis of the stronger studies (4 or more quality criteria met) alone also shows no statistically significant difference in inpatient mortality (OR $1.52,95 \% \mathrm{Cl} 0.86$ to 2.68 ) or mortality to longest follow up (OR $1.08,95 \% \mathrm{Cl} 0.71$ to 1.65 ). Given that the intervention involves a removal of some degree of medical supervision the experimental hypothesis of these studies is in effect 'no difference'. The confidence intervals are wide and the results of the stronger studies suggest a possible trend to increased inpatient mortality in the NLU and so the evidence to support the hypothesis of no difference is weak.

As inpatient mortality potentially involves different lengths of follow up for the groups compared, studies that reported outcomes to a fixed period from study entry were examined. Four studies provided data to 3 months ( 3 trials) or six months ( 3 trials) from admission. There was no statistically significant difference in mortality within 3 months of admission (OR $1.6095 \% \mathrm{Cl} .93$ to 2.75 ). There was no statistically significant difference in mortality within 6 months of admission (OR $0.96,95 \% \mathrm{Cl} .63$ to 1.47). The pattern of results is consistent with deaths occurring earlier in the NLU group although no study reported hazard of death as an outcome and no results were near significance at the conventional level of $p<0.05$.

\section{Outcome: Discharge to institutional care}

Seven studies reported discharge to institutional care and 3 reported institutionalisation at follow up beyond the index admission (90 days post admission for Griffiths 2000, 180 days for Griffiths 2001 and Steiner 2001). Odds of being discharged to institutional care were reduced for patients allocated to the NLU (OR $0.4495 \% \mathrm{Cl} 0.22$ to 0.89 ) although analysis of the three stronger studies alone does not show a clear benefit from the NLU (OR 0.88 $95 \% \mathrm{Cl} 0.54$ to 1.43$)$.

A combined outcome of death or discharge to institutional care (6 studies) was constructed to correct for the impact of inpatient death since different numbers died in each group and they might otherwise have been discharged to nursing homes. The odds of 
death or institutional care were reduced for those allocated to the NLU (OR $0.7195 \% \mathrm{Cl} 0.53$ to 0.95 ) but this is not supported by the 4 stronger studies alone (OR $1.0495 \% \mathrm{Cl} 0.72$ to 1.50$)$. There was no statistically significant difference in the odds of institutional care at longest follow up (OR $0.97,95 \% \mathrm{Cl} 0.60$ to 1.58 ).

\section{Outcome: Functional status at discharge}

Six studies reported measures of functional status or improvement in functional status at discharge from the index admission. Five studies reported improvement in the Barthel Index from admission to discharge (Griffiths 1995, Walsh 1999, Griffiths 2000, Griffiths 2001, Steiner 2001). One reported nursing dependency at discharge (Pearson 1988b).

Patients discharged from NLUs had better functional status at the point of discharge than controls (Standardized Mean Difference (SMD) $0.35,95 \% \mathrm{Cl} 0.16$ to 0.53 ). In all studies, the mean difference favoured the NLU. This conclusion was not sensitive to study quality with a benefit for the NLU group also demonstrated by the stronger studies alone (SMD $0.2295 \% \mathrm{Cl} 0.05$ to 0.39 ) albeit of a smaller magnitude. This finding could be influenced by differences in mortality with more dependent (sicker) patients dying as opposed to being discharged dependant. Separate analysis of the four studies reporting change in functional status (and therefore less affected by any baseline differences in function and differences in mortality) also showed that patients discharged from the NLU benefit (SMD 0.32, 95\% Cl 0.1 t10 0.54).

\section{Outcome: Length of hospital stay}

Nine studies reported on length of stay inpatient stay (i.e. in the original facility or NLU). Eight studies reported length of stay to first discharge home. One study (Bowcutt 2000) reported only length of stay in hospital where large numbers of patients from the control group study were discharged to rehabilitation facilities outside the original hospital. This length of stay to first discharge home could not be determined. For three studies (Pearson 1988a Pearson 1988b, Steiner 2001) figures for length of stay in hospital and length of stay to first discharge home were reported separately, as a small number of patients undergoing usual care were discharged via community hospitals. In the case of studies where rates of transfer to rehabilitation settings in another facility was negligible, length of stay to fist discharge home was taken to be the same as length of stay in hospital (Hall 1975; Griffiths 1995; Walsh 1999; Griffiths 2000; Griffiths 2001).

All but one study showed the NLU to have longer stays and in most cases the increase in length of stay was significant. The only exceptions were Walsh 1999 where there was a non-significant increase in length of stay and Griffiths 1995 where the NLU group had substantially (but non significant) reduced hospital stay. Meta-analysis indicates length of stay to discharge from hospital was significantly increased for patients cared for in NLUs with a weighted mean difference (WMD) of 7.37 days $(95 \% \mathrm{Cl} 2.86$ to 11.88 days). However there was significant heterogeneity among the weaker studies. Analysis of the stronger studies alone confirms the finding that length of stay was increased (WMD 13.41, 95\% Cl 8.54 to 18.29 days).

The increase in stay was partly accounted for by stays in other facilities among the control group. Stay until first discharge home is increased by 5.13 days (WMD) which does not quite achieve statistical significance $(95 \% \mathrm{Cl}-0.5$ days to 10.76 days). Bowcutt 2000 did not report on length of stay until first discharge home and it seems likely that the 33/94 patients in the control group discharged to rehabilitation facilities would contribute a substantial number of days stay. However, the results of other studies were consistent and analysis based on the four stronger studies alone confirms an increased length of stay until first discharge home (WMD 8.78 days, $95 \% \mathrm{Cl} 2.93$ to 14.63 days).

As there is evidence of skewed distributions, with standard deviations close to the mean in most cases, meta-analysis may be biased and so these analyses should be viewed as tentative.

\section{Outcome: Readmission}

Five studies reported early re admissions to hospital (within 4 weeks / 30 days of discharge). Odds of readmission were reduced for patients from the NLU (OR $0.5295 \% \mathrm{Cl} 0.34$ to 0.80 ). Analysis of the three stronger studies indicates a similar benefit but does not achieve statistical significance (OR $0.6395 \% \mathrm{Cl} 0.36$ to 1.12).

Outcome: Self reported quality of life / general health status at discharge

Five studies reported a measure of general health status at discharge. Three reported change scores (from admission to discharge) using an abbreviated version of the Nottingham Health Profile (the NHPD) (Griffiths 1995, Griffiths 2000, Griffiths 2001). Two reported a life satisfaction score at discharge (Pearson 1988a, Pearson 1988b). Of these studies two had poor (below 80\%) follow up (Griffiths 1995, Griffiths 2000) of which one was below 50\% (Griffiths 1995). Two studies reported quality of life at six month follow up (Pearson 1998b, Steiner 2001). Follow up fell below $80 \%$ for this outcome in two studies which reported change scores (Griffiths 1995 and Griffiths 2000) and for the two studies reporting six month follow up (Pearson 1988b, Steiner 2001)

The NLU was associated with better health status at the point of discharge (SMD $0.28,95 \% \mathrm{Cl} 0.09$ to 0.48 ). One individual study reported significant benefit to the NLU group (Griffiths 2001) and this was the study with the highest quality rating of this group. The NLU group showed better outcomes in all but one study (Griffiths 1995) and analysis of the two stronger studies alone shows a benefit from the NLU based on change scores (SMD $0.3395 \% \mathrm{Cl} 0.01$ to 0.67), which nears significance.

Steiner 2001 found no significant difference at six months (mean difference in score 0.9 95\% $\mathrm{Cl} 0.7$ to 2.4 ) as did Pearson 1988b (mean difference in score 0.5 no $\mathrm{Cl}$ given), although in both cases results favoured the NLU. However, since both of these results are based on very low follow up and neither is based on change scores to mitigate against pre test differences, little can be made of these findings.

Outcome: Psychological wellbeing

Three studies reported psychological well-being, in all cases measured by change in the 12-item General Health Questionnaire (GHQ) from admission to discharge. Only one study had a follow up of greater than $80 \%$ (Griffiths 2001) while one had a follow up of below 50\% (Griffiths 1995). Patients discharged from the NLU showed a greater improvement in wellbeing (SMD $0.3695 \% \mathrm{Cl}-0.03$ to 0.74 ) although this did not reach statistical significance. Analysis of the two stronger studies alone gave similar results (SMD 0.25, $95 \% \mathrm{Cl} 0.03$ to 0.52 ). 


\section{Outcome: Satisfaction with care}

Three studies reported measures of patient satisfaction Two used the Newcastle satisfaction with nursing scale (Griffiths 2000; Griffiths 2001) and one a patient services checklist (Pearson 1988b). In all cases response fell below $80 \%$ and for $2 / 3$ studies (Griffiths 2000; Griffiths 2001) follow up was below $60 \%$. Patients experiencing the NLU were more satisfied than those experiencing usual care (SMD $0.22,95 \% \mathrm{Cl}-0.03$ to 0.46 ) although the result does not quite achieve significance. No individual studies achieved significance but in all cases outcomes for the NLU were favourable. Results of the two stronger studies confirmed the trend (SMD 0.19, $95 \% \mathrm{Cl}-0.11$ to 0.48 ) although the suggestion of benefit is more equivocal.

\section{Comparison 2: NLU vs. Intensive Care Unit (ICU)}

A single study (Daly 1995) compared a NLU for the chronically critically ill with conventional care in an ICU. In patient mortality was lower for the NLU but not significantly so (OR $0.6295 \% \mathrm{Cl} 0.35$ to 1.10). Long term follow up (over variable periods up to 24 months) is reported for a sub sample. This shows no overall difference between the NLU and usual care (OR $0.895 \% \mathrm{Cl} 0.40$ to 1.59). There was no difference in proportion discharged to institutional care (OR $0.61,95 \% \mathrm{Cl} .0 .30$ to 1.25 ). Length of stay to first discharge home did not differ (WMD 2 days, $95 \% \mathrm{Cl} 10.96$ to -6.96 days). Early readmission rate (within 21 days) was lower for the NLU (OR 0.33 $95 \% \mathrm{Cl} 0.12$ to 0.94$)$.

Costs and resource use. (Table 2, Table 3)

Seven studies reported data on costs or charges for providing services. No study reported a wider (e.g. societal) perspective. For four (Daly 1995, Griffiths 2000, Griffiths 2001, Steiner 2001) comprehensive costs of providing services were identified although for one (Steiner 2001) many variable costs were aggregated at a care group level and so may not reflect true costs. For two studies (Pearson 1988a, 1988b) little detail is given of the methods used although both appear to have used average costs ward costs per bed and did not take into account any individual differences in resource use (e.g. tests, investigations, therapies). In one study (Bowcutt 2000) it was unclear if the figures given were based on costs or hospital charges, which can differ widely. In all cases the perspective was that of the acute care provider and no attempt was made to identify costs to patient or carers other than direct charges for services.

In most studies, daily cost of care (average cost bed stay / average length of stay) was lower for the NLU group. The exception to this was Steiner 2001 where daily costs attributed to the NLU were higher than for controls. In this study the unit cost attributed to the NLU included laboratory tests and other variable costs but these were apportioned between wards in a directorate and it was not clear if the cost reflected actual resource use in the NLU. Where studies reported details on resource use daily use of laboratory tests and investigations and other therapies (including medicine) was generally lower for the NLU (Daly 1995, Griffiths 2000, Griffiths 2001, Steiner 2001) with the exception of physiotherapy (Griffiths 2000, Griffiths 2001, Steiner 2001). Use of medically qualified staff was reduced (Griffiths 1995, Griffiths 2000, Griffiths 2001, Steiner 2001). Nurse staffing was generally equivalent in terms of overall numbers where reported (Griffiths 1995, Griffiths 2000, Griffiths 2001). The precise composition of the nursing team varied with higher numbers of senior staff than control wards (Griffiths 2000, Griffiths 2001) but in some cases lower overall numbers of qualified nurses (Daly 1995 Griffiths 2000).

Estimated costs of inpatient care for the NLU were higher than usual care for all UK studies, mainly due to the longer inpatient stay. Estimated costs of care on the NLU were lower than usual care for US based studies mainly due to costs /charges being lower for the NLU. The major determinant of total cost of care was the length of stay and in five of seven studies the more expensive model of care was that which involved longer stay. The exceptions to this are Pearson 1988a and Bowcutt 2000. For Pearson 1988a there was little difference in stay and little difference in costs. Recalculation based on figures quoted in the paper for daily costs (average stay X average daily costs) suggests that the cost for the treatment group is nearly identical to that for the control group. Bowcutt 2000 gives a large cost saving for the NLU despite slightly increased length of stay but there is some doubt about whether costs to the hospital or charges to the patient / insurer are the basis of the estimates given. Charges may have a different relationship to cost for each model of care and thus provide a poor estimate of difference.

Three UK studies reported on costs after discharge. Griffiths 2000 and Griffiths 2001 found lower costs for the NLU group in the month after discharge. However, savings would have to be maintained over extended periods to balance increased inpatient costs and patients from the NLU group were discharged later and so costs may simply have been displaced from community to acute hospital services. Steiner 2001reported costs over six months and found no substantial change from the difference in cost at discharge suggesting that there is no accumulating cost saving over time.

\section{DISCUSSION}

Ten studies were found which met the review criteria and provided data on patient outcomes, resource use or cost. The quality of studies is variable but overall results indicate that at the point of discharge from inpatient care, patients discharged from the NLU are more independent in terms of functional status and experience greater wellbeing. Fewer patients are discharged to institutional care although this benefit is not sustained by longerterm follow up (up to six months) and there is a reduction in early readmission for patients discharged from the NLU. Studies done in the UK suggest that the increased time spent in hospital for those discharged from the NLU make this more expensive than traditional care. In the US studies lower costs or charge for the NLU make this appear the cheaper option. Some of these results are sensitive to study quality and generally higher quality studies alone give more equivocal results. However, despite the apparent heterogeneity of patient groups, settings and implementation of NLU the trends of results are consistent for most studies on most outcomes irrespective of study quality. This review confirms that trends observed in individual studies may reflect real differences although the possibility of bias cannot be fully discounted.

NLUs can provide care that is intermediate between acute hospitals and home. In the more recent UK based studies control patients spent an average of between 18.2 and 42 days in acute care facilities (Walsh 1999, Steiner 2001, Griffiths 2001, Griffiths 2000). If this is regarded as the stay that patients in the NLU would otherwise have, it is clear the NLU succeeds in substituting for a considerable acute stay. Similarly in the one recent US study set in sub-acute care (Bowcutt 2000) the NLU substituted for an average 9.1 days of 
acute care. Daly 1995 demonstrated that a NLU for the chronically critically ill could substitute for 50.6 days of acute care (including time spent in ICU). However, NLUs appear to substitute for other transitional facilities such as community hospitals in some cases since for some control patients the index admission included a period of stay in such facilities whereas it was rare for patients from NLUs. The NLU also substitutes for a period of home care in some cases since total inpatient stay is 5.13 days longer. Since the aim is to be intermediate between hospitals and home this suggests that, in this regard, the NLU serves its designated function.

There is some evidence of benefit. There is evidence that patients are less likely to be discharged to institutional care from the NLU. This conclusion is sensitive to the quality of included studies and is not clearly supported by the higher quality research, although the trend across all studies is consistent. Patients discharged from the NLU are more independent in terms of functional status. Other measures of general health status and psychological well-being also point to patients having improved status at the point of discharge from the NLU although the quality of this evidence is poor due to low follow up in many studies. The NLU also reduces the number of early re-admissions. However, there is no evidence that benefit is maintained over the medium to long term as there is no difference in the number in institutional care by the end of follow up (typically six months).

It may be that patients are better at point of discharge from the NLU as they have stayed longer. This seems unlikely to be the sole explanation, since the effects observed are relatively large for the proportionately small increase in stay. Even if this is the case, providing the additional time is beneficial since adverse events like early rehospitalisation are intrinsically undesirable if they are avoidable. Avoidance of institutionalisation in the short term alone is a less clear benefit and service users would need to determine the value of postponing institutionalisation for only a short time.

There was no evidence of adverse effects in terms of mortality to longer follow-up. However, for inpatient (early) mortality the confidence intervals are wide and the trend of results is unfavourable to the NLU with 3 of the 4 better quality studies comparing the NLU to general inpatient care showing a nonsignificant increase. Although this could be a product of increased length of stay or sampling error there is insufficient evidence regarding the impact of the NLU on early mortality to ddetermineits safety definitively.

The UK studies suggest that the NLU is more expensive than usual care to acute care providers although there are cost savings after discharge. It seems unlikely in view of other findings that these are maintained for sufficiently long to equalise costs. Both US studies show cost savings but the robust evidence was derived from a single study comparing the NLU to intensive care. The basis of the cost savings identified in the study in sub-acute care (where the NLU was compared to general acute care) was less clear but does point to potentially reduced costs particularly since stays in rehabilitation units were not included in costs for the usual care group.

\section{AUTHORS' CONCLUSIONS}

\section{Implications for practice}

The NLU functions as a form of intermediate care and patients who are discharged from it may have higher levels of function and well- being. It is unclear if this benefit is simply a product of an increased stay and so the claim of the NLU to be positively therapeutic is untested. Although no statistically significant adverse effects were noted there was a trend to increased inpatient mortality for the NLU group among the stronger studies. This finding was not reflected in the weaker studies nor in longer term follow up. Again this may be a product of increased length of stay but the possibility of increased early mortality in the NLU group cannot be discounted. However, there is no clear evidence to support the fears expressed by some (Grimley Evans 2001) that NLUs represent a retrograde step, which leads to inadequate rehabilitation for older people.

In the UK extra resources have been identified for the provision of intermediate care (DoH 2001) and in the US the establishment of sub-acute / intermediate care in skilled nursing facilities can generate revenue for providers over and above that for an acute admission (Griffiths 1997). The NLU is one of a range of possible services in which additional resources could be invested. Evidence for other forms of inpatient intermediate care is scant or nonexistent. Although NLUs have previously been singled out as being supported by weak evidence, the findings of this review give some basis on which the NLU can be supported. The evidence is certainly far stronger for the NLU than for intermediate care in care homes (Ward 2003). However, generalisation from this evidence for the development of new services must be made with caution. Despite the consistency of results, the services described as NLUs are complex and diverse and attention must be given to the detailed implementation in local circumstances. Certainly the effectiveness of NLUs should not be assumed when developing new services.

Some common features do emerge from the services described. The majority of evidence for NLU derives from what are best described as demonstration units and in all cases there was additional preparation for staff either in terms of advanced qualification for some or all practitioners, specific skills training or wider programmes of practice development. The NLU, as evaluated, does not necessarily entail a net reduction in resource use and evidence from the UK suggests that total resource use in the inpatient setting is increased. Rather the NLU involves an alteration in the way resources are used and an alteration in composition of the healthcare team. In particular, the skill mix of the nursing workforce has generally been enriched and not down graded, even where overall numbers may be reduced. Generalisation from this evidence can only be to adequately resourced units.

There was an active attempt to assess suitability in terms of medical stability in all cases and potential to benefit from the NLU in most cases. With the exception of Daly 1995, suitability of patients referred from a larger pool was aassessedusing very broad criteria. Further aassessmentof suitability was in large part subjective. Attention needs to be paid to this in developing services. Despite the shortcomings, those developing services would be well advised to look to detailed admission criteria published in some accounts (Evans 1994, Daly 1995, Griffiths 1998 ; NLIU 1999) even though these accounts do tend to articulate who is unsuitable more clearly than who is likely to obtain most benefit (Griffiths 2000). It is far from clear that the criteria used would distinguish suitable patients in an undifferentiated post acute population who had not been subject to initial referral.

Since costs are largely determined by local circumstances, it would be unwise to draw to general a conclusion. Nonetheless, it seems that the NLU may lead to an overall increase in resource use during 
the index admission where average stay is extended beyond that incurred by those under usual care. The specific resources used may change but the only consistent finding of overall decrease is use of medical personnel. Resource use after discharge may be reduced but not significantly so. The economic basis of sub acute units in the USA in particular is complex. Payments to the provider for the initial acute hospitalisation may be fixed under prospective payment systems. Transfer to a skilled nursing facility for sub-acute care can generate additional revenue to the care provider, as it is reimbursable in addition to the acute stay. Hence, even if it was a more costly option in terms of total resources used it might in fact generate more revenue to the provider. A similar situation may occur in the UK under the new 'payments by results' system if the post acute stay becomes identified as a different eepisodefrom the initial aactuateadmission.

\section{Implications for research}

More evidence from well-conducted trials is required to fully determine safety in the NLU compared to usual care. This review did not set out to compare the NLU with other forms of inpatient intermediate care although it is clear that usual post acute care can also incorporate periods of stay in environments such as community hospitals that might be considered as such. The searches conducted for this review would have identified studies where patients were assigned directly to the NLU or another form of intermediate care and none were found. Thus, it remains unclear which services are best suited to which patients and which configuration of services represents the most cost effective solution. More research is required.
More evidence is required identifying criteria for suitability for NLU (as opposed to other forms of intermediate care) and to determine the cost effectiveness of the NLU relative to other forms of intermediate care. In determining cost effectiveness, it will be important to recognise that any service that sits at a boundary between different service providers is in danger of generating perverse incentives with the solution to the equation for cost effectiveness varying according to which providers perspective is taken.

The perspective of service users has not been fully considered as yet, although in addition to the weak but positive evidence on satisfaction presented here there has been some qualitative research, which gave a broadly favourable view of the NLU (Wiles 2003). However, if decisions are to be made regarding the merit of investing in NLUs in order to gain (for example) a short term delay in admission to a nursing home, a wider consideration of both client and carer perspectives on the matter is required.

\section{ACKN OWLEDGEMEN TS}

Thank you to the authors who provided additional information about their studies - in particular Barbara Daly, Alan Pearson and Bronagh Walsh who provided us with detailed responses on a number of points. We would also like to acknowledge Sasha Shepperd, Leigh Kinsmen and Helen Thomas for their helpful comments on the initial publication of this review. 


\section{R E F E R E N C E S}

\section{References to studies included in this review}

\section{Bowcutt 2000 \{published data only\}}

Bowcutt M, Andrews BC, Kaye J. Subacute care: a competitive response to providing geriatric care. Journal of Nursing Adminisatration 2000;30(6):300-303.

Daly 1995 \{published data only (unpublished sought but not used)\} Daly BJ, Phelps C, Rudy EB. A nurse-managed special care unit. Journal of Nursing Administration 1991;21(7/8):31-8.

Douglas S, Daly B, Rudy E, Song R, Dyer MA, Montenegro H. The cost-effectiveness of a special care unit to care for the chronically critically ill. Journal of Nursing Administration 1995;25(11):47-53.

Douglas S, Daly BJ, Rudy EB, Sereika SM, Menzel L, Song R, et al. Survival experience of chronically critically ill patients. Nursing Research. 1996, 45(2):73-7. Survival experience of chronically critically ill patients. Nursing Research 1996;45(2):73-77.

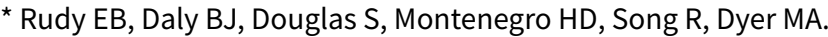
Patient outcomes for the chronically critically ill: special care unit versus intensive care unit [see comments]. Nursing Research 1995;44(6):324-31.

\section{Davies 1994 \{published data only\}}

Davies SM. An evaluation of nurse-led team care within a rehabilitation ward for elderly people. Journal of Clinical Nursing 1994;3(1):25-33.

\section{Griffiths 1995 \{published and unpublished data\}}

Griffiths P. Clinical outcomes for nurse-led in-patient care. Nursing Times 1996;92(9):40-3.

Griffiths P. Evaluation of nurse-led in-patient care. Nursing Times 1995;91(43):34-7.

* Griffiths P, Evans A. Evaluating a nursing led in-patient service: an interim report. London: King's Fund, 1995.

Griffiths 2000 \{published and unpublished data\}

* Griffiths P, Wilson-Barnett J, Richardson G, Spilsbury K, Miller $F$, Harris R. The effectiveness of intermediate care in a nursing-led in-patient unit. International Journal of Nursing Studies 2000;37(2):153-61.

Griffiths, P. Evaluation of a Nursing-led In-patient Unit [PhD Thesis\}. London: King's College, University of London, 1998.

Griffiths, P. Nursing-led in-patient units for intermediate care: a survey of multidisciplinary discharge planning practice. Journal of Clinical Nursing 2001;1(3):322-330.

Richardson G, Griffiths P, Spilsbury P, Wilson-Barnett J, Batehup L. Economic evaluation of a nursing-led intermediate care unit.. International Journal of Technology Assessment in Health Care 2001;17:442-450.
Griffiths 2001 \{published and unpublished data\}

* Griffiths P, Harris R, Richardson G, Hallett N, Heard S, WilsonBarnett J. Substitution of a nursing-led inpatient unit for acute services: randomised controlled trial of outcomes and cost of nursing-led intermediate care. Age and Ageing 2001;2001(30):483-8.

NLIU Evaluation Project Team. Substitution of "Nursing-led Inpatient Units" for Acute Services. Vol. Report OM438., London: North Thames Regional health Authority, 1999.

Hall 1975 \{unpublished data only\}

Alfano, G. A different kind of nursing.. Nursing Outlook 1988;36(1):34-39.

* Hall L, Alfons G, Rifkin E, Levine H. Final Report: Longitudinal Effects of an Experimental Nursing Process. New York: Loeb Center for Nursing and Rehabilitation (Unpublished), 1975.

Pearson 1988a \{published data only\}

Pearson A. Nursing at Burford: a story of change. Harrow: Scutari Press, 1992.

* Pearson A, Durand I, Punton S. The feasibility and effectiveness of nursing beds. Nursing Times 1988;84(47):48-50

Pearson A, Punton S, Durant I. Nursing Beds: An evaluation of the effects of therapeutic nursing. Harrow: Scutari Press, 1992.

\section{Pearson 1988b \{published data only\}}

Baker $\mathrm{H}$, Pearson A. The experience of patients in a professional nursing unit. Australian Journal of Advanced Nursing 1991;9(1):15-9.

Pearson A, Durant I, Punton S. Determining quality in a unit where nursing is the primary intervention. Journal of Advanced Nursing 1989;14(4):269-73.

Pearson A, Durant I, Punton S. Effects of admission to a nursing unit. Australian Journal of Advanced Nursing 1988;6(1):38-42.

Pearson A. Therapeutic nursing - transforming models and theories in action. Recent Advances in Nursing 1989;24:123-151.

* Pearson A, Punton S, Durant I. Nursing Beds: An evaluation of the effects of therapeutic nursing. Harrow: Scutari Press, 1992.

Steiner 2001 \{published and unpublished data\}

* Steiner A, Walsh B, Pickering RM, Wiles R, Ward J, Brooking JI, et al. Therapeutic nursing or unblocking beds? A randomised controlled trial of a post-acute intermediate care unit. $B M J$ 2001;322(7284):453-60

Walsh B, Steiner A, Pickering RM, Ward-Basu J. Economic evaluation of nurse led intermediate care versus standard care for post-acute medical patients: cost minimisation analysis of data from a randomised controlled trial. BMJ 2005;330::699.

Walsh B, Steiner A, Warr J, Sheron L, Pickering R. Nurse-led inpatient care: opening the 'black box'.. International Journal of Nursing Studies 2003;40(3):307-316. 
Wiles R, Postle K, Steiner A, Walsh B. Nurse-led intermediate care: an opportunity to develop enhanced roles for nurses?. J Adv Nurs 2001;34(6):813-21.

Wiles R, Postle K, Steiner A, Walsh B. Nurse-led intermediate care: patients' perceptions. International Journal of Nursing Studies 2003;40(1):61-71.

Walsh 1999 \{published and unpublished data\}

* Walsh B, Pickering R, Brooking J. A randomized controlled trial of nurse-led inpatient care for post acute medical patients: a pilot study. Clinical Effectiveness in Nursing 1999;3(2):88-90.

\section{References to studies excluded from this review}

Bachmann 1987 \{published data only\}

Bachman SS, Collard AF, Greenberg JN, Fountain E, Huebner TW, Kimball B, et al. An innovative approach to geriatric acute care delivery: the Choate-Symmes experience. Hospital \& Health Services Administration 1987;32(4):509-20.

Collard AF, Bachman SS, Beatrice DF. Acute care delivery for the geriatric patient: an innovative approach. Quality Review Bulletin 1985;11(6):180-5.

Barrett 2001 \{published data only\}

* Barrett J, Goh S, Todd C, Barclay S, Daza-Ramirez P, Vardulaki K. A description of an intermediate care service using routinely collected data. Journal of Nursing Management 2001;10:221-227.

\section{Bond 1989 \{published data only\}}

Bond J, Gregson B, Atkinson A, Newell D. The implementation of a multicentred randomized controlled trial in the evaluation of the experimental National Health Service nursing homes. Age \& Ageing 1989;18(2):96-102.

Bond J, Gregson BA, Atkinson A. Measurement of Outcomes within a multicentred randomized controlled trial in the evaluation of the experimental NHS nursing homes. Age and Ageing 1989;18:292-3012.

\section{Burl 1998 \{published data only\}}

Burl J, Bonner A, Rao M, Khan A. Geriatric nurse practitioners in long-term care:demonstration of effectiveness in managed care. Journal of the American Geriatrics Society 1998;46(4):506-10.

\section{Crotty 2005 \{published data only\}}

Crotty M, Whitehead CH, Wundke R, Giles LC, Ben-Tovim D, Phillips PA. Transitional care facility for elderly people in hospital awaiting a long term care bed: randomised controlled trial. BMJ 2005;331:(7525):1110.

\section{Kane 1989 \{published data only\}}

Kane RL, Garrard J, Skay CL, Radosevich DM, Buchanan JL, McDermott SM, et al. Effects of a geriatric nurse practitioner on process and outcome of nursing home care. American Journal of Public Health 1989;79(9):1271-7.
Landefeld 1995 \{published data only\}

Landefeld CS, Palmer RM, Kresevic DM, Fortinsky RH, Kowal J. A randomized trial of care in a hospital medical unit especially designed to improve the functional outcomes of acutely ill older patients. New England Journal of Medicine 1995;332(20):1338-.

Michael 2004 \{published data only\}

Michael R, Wheeler B, Wichmann H, Horner B, Downie J. The healthy ageing unit: a comparative controlled intervention. Journal of the Australasian Rehabilitation Nurses' Association (JARNA) 2005;8:(2):9-15.

Michael R, Wichmann H, Wheeler B, Horner B, Downie J. A multidisciplinary model of transitional rehabilitation in acute aged care. Journal of the Australasian Rehabilitation Nurses' Association (JARNA) 2004;7:(4):10-16.

Michael R, Wichmann H, Wheeler B, Horner B, Downie J. The healthy ageing unit: beyond discharge. Journal of the Australasian Rehabilitation Nurses' Association (JARNA) 2005;8:(4):8-16.

Mullen 1995 \{published data only\}

Anon. Huddersfield NHS Trust Nurse Led Bed Unit (Report). Huddersfield NHS Trust, 1995.

* Mullen, C. Delivering Health Care In a Nurse-Led Practice Development Unit. NHS Executive Value for Money Update 1995;14:6.

Nelson 1984 \{published data only\}

Nelson D. Nurse managed rehabilitation. Nursing Management (Chicago) 1984;15(3):30-39.

Pioro 2001 \{published data only\}

Pioro MH, Landefeld CS, Brennan PF, Daly B, Fortinsky RH, Kim U, et al. Outcomes-based trial of an inpatient nurse practitioner service for general medical patients. Journal of Evaluation in Clinical Practice 2001;7(1):21-33.

Shepperdson 2001 \{published data only\}

Shepperdson B, Phelps K, Turner D, Barrett A, Wileman C. District nurse-led beds: an alternative to care at home. British Journal of Community Nursing 2001;6(9):472-9.

Sitzia 1998 \{published data only\}

Sitzia J, Haddrell V, Rice-Oxley M. Evaluation of a nurse-led multidisciplinary neurological rehabilitation programme using the Nottingham Health Profile. Clinical Rehabilitation 1998;12(5):389-94.

von Sternberg 1997 \{published data only\} von Sternberg T, Hepburn K, Cibuzar P, Convery L, Dokken B, Haefemeyer J, et al. Post-hospital sub-acute care: An example of a managed care model. Journal of the American Geriatrics Society 1997;45(1):87-91.

Wilce 1988 \{published data only\}

Wilce G. A place like home: a radical experiment in health care. London: Bedford Square Press, 1988. 


\section{Additional references}

\section{DoH 2001}

Department of Health. National Service Framework for Older People. London: Department of Health, 2001.

\section{Evans 1994}

Evans A, Griffiths, P. Developing a nursing led in-patient service. London: King's Fund, 1994.

\section{Goddard 2000}

Goddard M, McDonagh M, Smith D. Planning for Hospitals and Related Services. Consultation Document on the Findings of the National Beds Inquiry. In: Department of Health, editor(s). Shaping the Future NHS: Long Term Care. London: Department of Health, 2000.

\section{Griffiths 1997}

Griffiths P. In search of therapeutic nursing: subacute care. Nursing Times 1997;93(26):54-5.

\section{Griffiths 1998}

Griffiths P, Wilson-Barnett J. The effectiveness of 'nursing beds': a review of the literature. Journal of Advanced Nursing 1998;27(6):1184-92. [MEDLINE: 98327003]

\section{Grimley Evans 2001}

Grimley Evans J, Tallis RC. A new beginning for care for elderly people?. British Medical Journal 2001;322(7290):807-808.

\section{Hall 1969}

Hall LE. The Loeb Centre for Nursing and Rehabilitation, Montefiore Hospital and Medical Center, Bronx, New York. International Journal Of Nursing Studies 1969;6:81-97.

\section{Knowelden 1991}

Knowelden J, Westlake L, Wright KG, Clarke SJ. Peterborough Hospital at Home: an evaluation. Journal of Public Health Medicine 1991;13(3):182-8. [MEDLINE: 92068559]

\section{Martin 1991}

Martin F, Oyewole A, Moloney A. A randomized controlled trial of a high support hospital discharge team for elderly people. Age and Ageing 1991;23:228-34.

\section{McCormack 1992}

McCormack B. A case study identifying nursing staffs' perception of the delivery method of nursing care in practice on a particular ward. Journal of Advanced Nursing 1992;17(2):187-97. [MEDLINE: 92210928]

\section{NLIU 1999}

NLIU Evaluation Project Team. Substitution of "Nursing-led In-patient Units" for Acute Services. Vol. Report No. OM438. London: North Thames Regional health Authority, 1999.

\section{Pearson 1992}

Pearson A, Punton S, Durant I. Nursing Beds: An evaluation of the effects of therapeutic nursing. Harrow: Scutari Press, 1992.

\section{Shepperd 2004}

Shepperd S, Parkes J, McClaren J, Phillips C. Discharge Planning From Hospital To Home. Cochrane Database of Systematic Reviews 2004, Issue 1. [Art. No.: CD000313. DOI: 10.1002/14651858.CD000313.pub2.]

\section{Shepperd 2005}

Shepperd S, Iliffe S. Hospital-at-home versus in-patient hospital care. Cochrane Database of Systematic Reviews 2005, Issue 3. [Art. No.: CD000356. DOI: 10.1002/14651858.CD000356.pub2.]

\section{Steiner 1997}

Steiner A. Intermediate care: a conceptual framework and review of the literature. London: King's Fund, 1997.

\section{Ward 2003}

Ward D, Severs M, Dean T, Brooks N. Care home versus hospital and own home environments for rehabilitation of older people. Cochrane Database of Systematic Reviews 2003, Issue 2. [Art. No.: CD003164. DOI: 10.1002/14651858.CD003164.]

\section{Wiles 2003}

Wiles R, Postle K, Steiner A, Walsh B. Nurse-led intermediate care: patients' perceptions. International Journal of Nursing Studies 2003;40(1):61-71.

\section{Zwarenstein $\mathbf{2 0 0 0}$}

Zwarenstein M, Stephenson BJ, Johnston L. Effects of case management on outcomes of care. Cochrane Database of Systematic Reviews 2000, Issue 4. [Art. No.: CD002797. DOI: 10.1002/14651858.CD002797.]

\section{References to other published versions of this review Griffiths 2005}

Griffiths P, Edwards M, Forbes A, Harris R. Post-acute intermediate care in nursing-led units: a systematic review of effectiveness. International Journal of Nursing Studies 2005;42(1):107-116.

* Indicates the major publication for the study

\section{CHARACTERISTICS OF STUDIES}

Characteristics of included studies [ordered by study ID]

Bowcutt 2000

$\begin{array}{ll}\text { Methods } & \text { Study design: RCT } \\ & \text { Unit of allocation: Individual patient }\end{array}$


Bowcutt 2000 (Continued)

Unit of analysis: Individual patient

Power calculation: Not done

Concealment*: Unclear

Follow-up*: $98 \%$

Blinded assessment ${ }^{\star}:$ done for length of stay and discharge destination

Baseline*: Not clear. Large difference in mean age between groups.

Reliable outcomes*: done for length of stay and discharge destination

Contamination*: Unlikely - control patients not exposed to NL

Intention to treat analysis* ${ }^{*}$ unclear

Participants

Elderly ('geriatric') sub-acute (defined by Joint Commission on Accreditation of Healthcare Organisations survey criteria) patients who would otherwise be admitted/remain on acute medical / surgical services. Inclusion criteria 'mentally alert' (not defined), no contagious diseases, not a primary psychiatric problem and $50+$ years of age.

96 Treatment $38.54 \%$ male, mean age 77.5

95 C $37.89 \%$ male, mean age 68.4

Follow up $100 \%$ of those reported.

\section{Interventions}

Unit / setting: 20 bed self contained sub-acute care unit within an acute hospital (USA).

Care management: Program director (nurse manager) headed weekly review meetings with interdisciplinary team and patients / families to plan and evaluate care.

Nursing Team: Day shift comprised 2 Registered Nurses, 2 Licensed Practical Nurses and 2 Clinical Nursing assistants plus a CNS and nurse manager. Night shift 1 RN, 2 Licensed Practical Nurses and 2 Nursing assistants.

MD team: A specialist multidisciplinary team (geriatric clinical nurse specialist, dietitician, physical therapist, speech and hearing therapist, social worker, activity specialist and chaplain plus general nursing and medical staff) headed by a nurse manager/ Other therapy was available on a case by case basis.

Education / preparation for staff: Orientation to sub acute / geriatric care + in service training Other: Aimed to create a homely environment with patients encouraged use collective dining area and bring in personal items such as bedspreads. An activity program included book groups and games, craft, art etc.

Control: general medical / surgical wards

\begin{tabular}{|c|c|c|}
\hline Outcomes & $\begin{array}{l}\text { Length of stay } \\
\text { Costs } \\
\text { Place of discharge }\end{array}$ & \\
\hline Notes & $\begin{array}{l}\text { Quality score } 2 / 5 \text { (blin } \\
\text { liable) }\end{array}$ & $\mathrm{ng}$ / reliability not rated as all outcomes for this study are intrinsically blind / re- \\
\hline \multicolumn{3}{|l|}{ Risk of bias } \\
\hline Bias & Authors' judgement & Support for judgement \\
\hline Allocation concealment? & Unclear risk & B - Unclear \\
\hline
\end{tabular}

\section{Daly 1995}

Methods

Study design: CCT using permuted block design 'biased coin' in a 1:2 (control:treatment). Coin toss determines first allocation. If first allocation is $C$ then next 2 are Treatment. If Treatment a second coin toss determines order of next two (1 Treatment and $1 \mathrm{C})$.

Unit of allocation: patient

Unit of analysis: patient

Power calculation: Not done 
Daly 1995 (Continued)

Concealment*: Not done

Follow-up*: 100\%

Blinded assessment ${ }^{\star}$ : done for length of stay and discharge destination, unclear for data from chart re-

view

Baseline*: done - no substantial differences between groups. Slight difference on respiratory complica-

tions in favour of control

Reliable outcomes*: done for length of stay and discharge destination, done for chart review $(90 \%+$

agreement)

Contamination*: Unlikely - control patients not exposed to NL

Intention to treat analysis*: Unclear

Participants

'Chronically critically ill' defined as ICU stay $>5$ days, no instability in past 3 days, no vasopressors or arterial monitoring referred from ICU APACHE II score 15 or less, TISS class II or III and not suitable for general nursing unit. Admitting diagnoses cardiovascular respiratory and neurological.

Mean age 64, mean ICU stay 16 days

TREATMENT 145

C 75

$100 \%$ follow for main outcomes.

Interventions

Unit / setting: 7 bedded unit in acute tertiary teaching hospital (USA)

Care management: Case management by unit nurse with use of unit based protocols for ventilator weaning,sedation, nutrition and pain management and primary nursing.

Nursing Team: 16 Registered Nurses (including case manager and a CNS) + 3 patient care assistants.

Typically nurse patient ratio 1:2 (per shift)

MD team: No interns / residents. Unit medical director and case manager perform daily 'rounds'.

Case manager presents at weekly inter-disciplinary case conference (composition not specified) and

arranges consultation from other disciplines as required.

Education / preparation for staff: 8 week training programme for case managers

Other: Private rooms / enclosed bed spaces and lighting dimmed when appropriate, low technology open visiting and overnight stays by relatives available. Family involvement in care encouraged. Staff management using a shared governance model.

Control: 12 bed Medical ICU / 18 bed Surgical ICU with (approximately) 1:1 Nurse patient ratio (per shift) + attending managed care with interns / residents. Nursing according to primary care model. Traditional staff management model. Environment 'traditional' ICU with open bed spaces and highly prominent technology.

$\begin{array}{ll}\text { Outcomes } & \text { In patient mortality } \\ & \text { Discharge destination } \\ & \text { Readmission (within 3 weeks) } \\ \text { Length of hospital stay } & \text { Number of infections per patient } \\ \text { Number of respiratory complications per patient } \\ \text { Number of life threatening complications per patient } \\ \text { Patient satisfaction } \\ \text { Charges / costs }\end{array}$

Notes Quality score $4 / 7$

\section{Risk of bias}

\begin{tabular}{lll}
\hline Bias & Authors' judgement & Support for judgement \\
\hline Allocation concealment? & Unclear risk & D - Not used \\
\hline
\end{tabular}




\section{Methods}

Controlled before and after study comparing NL pre / post implementation with 2 control wards Baseline Comparability: Not clear - length of stay and quality of care reported for 2 (1) control wards. Lengths of stay differs markedly

Blinded assessment: done for length of stay, not done for quality.

Reliable assessment: done for length of stay unclear for quality, satisfaction

Contamination: Unclear

Follow up: sample size and follow up are unclear.

\section{Participants}

Elderly care 'rehabilitation'. Patients over 75 with a range of diagnoses (examples given CVA, MI, pneumonia and hip fracture). Sample size not specified but pre and post length of stay data presented from 6 month periods. Data is presented from 53 nurses relating to job satisfaction.

Interventions Unit / setting: 18 bed unit in a satellite (non acute) hospital linked to (2 miles) a District General Hospital (UK).

Care management: Care managed in a single weekly interdisciplinary meeting chaired by a senior nurse. No routine medical assessment with primary nurse planning care and initiating medical involvement / referring to other disciplines.

Nursing Team: No detail given.

MD team: Included 'therapists' (Occupational Therapy and Physio) Social work and medics. No registrar / senior registrar input onto ward.

Education / preparation for staff: None described although the process of implementation is described as developing from within the unit (i.e. bottom up)

Other: Attempts to create less formal atmosphere (e.g. nurses did not wear uniforms).

Control: .Two 'similar' wards with routine medical care management.

\begin{tabular}{|c|c|}
\hline Outcomes & $\begin{array}{l}\text { Length of stay } \\
\text { quality of care } \\
\text { nurse job satisfaction } \\
\text { Process of interdisciplinary care }\end{array}$ \\
\hline Notes & Quality score: N/A \\
\hline Risk of bias & \\
\hline Bias & Authors' judgement Support for judgement \\
\hline Allocation concealment? & D - Not used \\
\hline
\end{tabular}

Griffiths 1995

Study design: RCT using 'Zellen's design' with double consent
Unit of allocation: Patient
Unit of analysis: Patient
Power calculation: Not done
Concealment*: Not done. Randomisation from open list prior to patient consent
Follow-up*: $84 \%$ of randomised patients consented. $100 \%$ of consented patients followed up.
Blinded assessment*: Done for length of stay and discharge destination. Not done for functional sta-
tus.
Baseline*: Baseline differences in functional status and abnormal assessment findings in favour of in-
tervention group. Statistical analysis (ANCOVA) attempted to correct for pre-test differences.
Reliable outcomes ${ }^{\star}:$ Done for length of stay and discharge destination. Not done for functional status
Contamination ${ }^{\star}$. Unlikely - control patients not exposed to NL
Intention to treat analysis ${ }^{*}:$ Analysis done on intention to treat basis

Participants

Post-acute patients referred from acute medical wards of tertiary teaching hospital and assessed as being medically stable and having a remediable nursing need. $75 \%$ female, mean age 77 years mean 
Griffiths 1995 (Continued)

acute stay 23 days. Stroke, cardiac problems and functional deficits most common cause for initial admission.

Treatment 71

Control 48

(84\% of assigned patients consented. Full follow up of consenting patients)

\begin{abstract}
Interventions Unit / setting: 13 bedded unit in split site tertiary / general acute care hospital (UK).
Care management: Nurses assessed suitability for admission and primary nurses on unit planned care. Unit manager chaired interdisciplinary meeting

Nursing Team: 1 primary nurse +7 other Registered nurses and 2 auxiliary nurses (nursing aides). Overall nurse patient ratio (from roster) 0.82 nurses per patient per day $79 \%$ qualified (Registered / Licensed nurses)

MD team: Physiotherapy, Occupational therapy and social work and medical officer (general practitioner or equivalent) + others including medicine on referral. Team meetings led by unit manager / primary nurse.

Education / preparation for staff: Team building and a series of away days prior to implementation. Training in physical assessment for senior staff (primary nurses + those assessing pt suitability). The service developed at the end of a long process of practice development and was developed through a bottom up mechanism.

Other: Interventions designed to promote more patient centred and informal environment such as staff wearing own clothes, patient representative on unit management / steering group.
\end{abstract}

Control: general medical (including elderly care) wards with equivalent nursing staff and routine medically managed care.

\begin{tabular}{ll}
\hline Outcomes & Length of stay \\
& Health status \\
psychological well-being & physical / functional dependence \\
place of discharge \\
mortality \\
readmission \\
complications
\end{tabular}

Notes Quality score 3/7

\title{
Risk of bias
}

\begin{tabular}{lll}
\hline Bias & Authors' judgement & Support for judgement \\
\hline Allocation concealment? & Unclear risk & D - Not used \\
\hline
\end{tabular}

\section{Griffiths 2000}

Methods

\author{
Study design: RCT using 'Zellen's design' with double consent \\ Unit of allocation: Patient \\ Unit of analysis: Patient \\ Power calculation: Done - powered to detect medium effect sizes \\ Concealment*: Not done. Randomisation from open list held remote from patients prior to patient con- \\ sent \\ Follow-up*: $77 \%$ of randomised patients consented. $100 \%$ of consented patients followed up. \\ Blinded assessment*: Done for length of stay and discharge destination. Not done for functional sta- \\ tus.

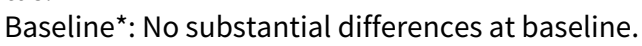 \\ Reliable outcomes ${ }^{\star}$ : Done for length of stay and discharge destination. Done for functional status - av- \\ erage kappa for each item of Barthel Index greater than .8.
}


Griffiths 2000 (Continued)

Contamination*. Unlikely - control patients not exposed to NLU

Intention to treat analysis*: Analysis done on intention to treat basis

Participants

Post-acute patients referred from acute wards (predominantly med / surgical) of tertiary teaching hospital, assessed as being medically stable and having a remediable nursing need. $63 \%$ female mean age 77 mean acute stay 25.2 days. Orthopaedic, gastrointestinal and neurological problems most frequent reasons for initial admission.

Treatment 97

Control 80

(77\% of assigned patients consented. Full follow up of consenting patients)

Interventions

Unit / setting: 24 bedded unit in satellite hospital providing care of the elderly and rehabilitation services linked to tertiary hospital on separate site (UK).

Care management: Nurses assessed suitability for admission and primary nurses on unit planned care.

Unit manager (nurse) chaired interdisciplinary meeting

Nursing Team: 3 primary nurses + other Registered nurses and nursing aides. 0.75 nurses per patient per day $61 \%$ qualified

MD team: Physiotherapy, Occupational therapy and social work and medical officer (general practitioner or equivalent) + others including medicine on referral. Team meetings led by unit manager / primary nurse.

Education / preparation for staff: Team building and a series of away days prior to implementation. Training in physical assessment for senior staff (primary nurses + those assessing pt suitability). The service developed at the end of a long process of practice development and was developed through a bottom up mechanism. No specific ongoing development orientation for new staff although some in service training on physical assessment.

Other: Interventions designed to promote more patient centred and informal environment such as staff wearing own clothes, patient representative on unit management / steering group. Occupational Therapy led activity group.

Control: Acute general wards (including elderly care) with 0.86 nurses per patient $75 \%$ qualified and routine medically managed care.

\begin{tabular}{ll}
\hline Outcomes & Length of stay \\
& Health status \\
& psychological well-being \\
physical / functional dependence & place of discharge \\
& mortality \\
& readmission \\
& complications \\
& Patient Satisfaction \\
& In hospital costs \\
& Post discharge costs \\
& Quality score $5 / 7$
\end{tabular}

\section{Risk of bias}

\begin{tabular}{lll}
\hline Bias & Authors' judgement & Support for judgement \\
\hline Allocation concealment? & Unclear risk & D - Not used \\
\hline
\end{tabular}

Griffiths 2001

$\begin{array}{ll}\text { Methods } & \text { Study design: RCT } \\ & \text { Unit of allocation: Patient }\end{array}$


Griffiths 2001 (Continued)

Unit of analysis: Patient

Power calculation: Done - powered to detect medium effect sizes

Concealment*: Done. Randomisation from opaque sealed envelopes opened after consent

Follow-up*: 99\%.

Blinded assessment ${ }^{\star}$ : Done for length of stay and discharge destination. Not done for functional sta-

tus.

Baseline*: No substantial differences at baseline.

Reliable outcomes*: Done for length of stay and discharge destination. Done for functional status - average kappa for each item of Barthel Index greater than .8 agreement $90 \%+$ on all items.

Contamination*. Unlikely - control patients not exposed to NL

Intention to treat analysis*: Analysis done on intention to treat basis

Participants

Post-acute patients referred from acute wards (predominantly medical / orthopaedic / surgical wards) of a district general hospital assessed as being medically stable and having a remediable nursing need. $67 \%$ female mean age 78 mean acute stay 15.2 days. Orthopaedic, gastrointestinal and neurological problems most frequent reasons for initial admission.

Treatment 89

Control 87

99\% follow up for main endpoints (discharge, in hospital mortality)

Interventions

Unit / setting: 19 bedded unit in district general hospital (UK)

Care management: Nurses assessed suitability for admission and primary nurses on unit planned care. Unit manager (nurse) chaired interdisciplinary meeting Nursing Team: 3 primary nurses + other Registered Nurses and nursing aides. 0.84 nurses per patient $63 \%$ qualified (Registered / Licensed Nurse)

MD team: physiotherapy, Occupational therapy and social work and medical officer (general practitioner or equivalent) + others including medicine on referral. Team meetings led by unit manager / primary nurse.

Education / preparation for staff: Newly appointed team at inception of project. Senior staff appointed involved in formal in service training in nurse practitioner' skills such as chest / abdominal assessment taking ECG, certifying death. Predominantly 'top down' development.

Other: Staff chose informal track suit style uniform to create less formal atmosphere.

Control : general surgical medical wards . 81 nurse per patient per day, $61 \%$ qualified

\begin{tabular}{ll}
\hline Outcomes & Length of stay \\
& Health status \\
& Psychological well-being \\
& Physical / functional dependence \\
place of discharge & mortality \\
Readmission & Complications \\
Patient Satisfaction & In hospital costs \\
\hline
\end{tabular}

Notes Quality score 6/7

\section{Risk of bias}

Bias Authors' judgement Support for judgement

Allocation concealment? Low risk A-Adequate


Study design: quasi random controlled trial based on terminal digit of accession number.

Unit of allocation: Patient

Unit of analysis: Patient

Power calculation: Not done

Concealment*: Unclear method of assignment was 'withheld from physicians'

Follow-up*: $94.6 \%$

Blinded assessment ${ }^{\star}$ : Done for length of stay and discharge destination. Not done for functional sta-

tus.

Baseline*: Differences noted in functional independence in favour of intervention group.

Reliable outcomes*: Done for length of stay and discharge destination. Not clear for functional status.

Contamination*. Possible for long term follow up - control patients readmitted to NL - but not substan-

tial (14 patients in total)

Intention to treat analysis*: Done

Participants

Patients post acute coronary event (MI, heart failure rhythm disorder) assessed as being medically stable and having a remediable nursing need.

Treatment 351 mean age 66.2 , 39\% Female mean 19.8 days post admission

Control 188 mean age 67.0, 40\% Female mean 20.1 days post admission

$94.6 \%$ of patients followed up for main outcome (death within 18 months)

Interventions

Unit / setting: $2 \times 40$ bed units attached to acute general / tertiary care teaching hospital Care management: Admission authorised by nurse manager . Care planned and managed by primary nurse.

Nursing Team: Described as all Registered Nurses. 1 RN per 8/10 patients during the day

MD team: No detail given - the role of other professions is described as advisory

Education / preparation for staff:

Other: Extensive descriptions are given of changes in the philosophy and approach to nursing and attempts to make the unit more informal and inviting (open visiting)

Control: Usual care in medically managed acute units

\begin{tabular}{ll}
\hline Outcomes & Lenght of stay \\
& Mortality to 18 months \\
& Independence \\
& Readmission \\
& Hospital charges \\
& Satisfaction \\
\hline Notes & Quality score $2 / 7$ \\
\hline
\end{tabular}

\section{Risk of bias}

\begin{tabular}{lll}
\hline Bias & Authors' judgement & Support for judgement \\
\hline Allocation concealment? & Unclear risk & D - Not used \\
\hline
\end{tabular}

Pearson 1988a

$\begin{array}{ll}\text { Methods } & \text { Study design: RCT } \\ & \text { Unit of allocation: Patient } \\ & \text { Unit of analysis: Patient } \\ & \text { Power calculation: Not done } \\ \text { Concealment*: Done. Randomisation from opaque sealed envelopes opened after consent } & \text { Follow-up*: } 82 \% \text { to } 6 \text { months }\end{array}$


Blinded assessment*: Done for length of stay and discharge destination. Not done for functional status.

Baseline ${ }^{\star}$ : Reported a difference in frequency using stairs before admission - direction and magnitude not specified.

Reliable outcomes*: Done for length of stay and discharge destination. Not clear for functional status.

Contamination*. Unlikely - control patients not exposed to NLU

Intention to treat analysis*: Unclear

\section{Participants}

Patients post internal fixation of hip fracture assessed as being medically stable and having a remediable nursing need. Patients aged $60+$ transfered after average 9.8 days acute stay (treatment group)

25 Control mean age $80,88 \%$ female

45 Treatment mean age $81,84 \%$ female

\section{Interventions}

Unit / setting: 9 bedded cottage hospital in rural setting

Care management: Senior nurse assessed patients, primary nurse planned and managed care

Nursing Team: Approximately 9 whole time equivalent qualified nurses +2 nursing assistants

MD team: Social worker, physiotherapist and Dr available on referral in advisory capacity

Education / preparation for staff: An extensive staff development programme (over 6 months) prior to changing to nurse-led care

Other: Removal of routine for patients day, informal atmosphere, nurses wore ordinary clothes.

Control: Usual care in medically managed acute wards and community hospitals

\begin{tabular}{ll}
\hline Outcomes & Length of stay \\
& Mortality \\
& Dependency \\
Life satisfaction \\
Nursing care quality \\
Cost of nursing staff
\end{tabular}

Notes Quality score 3/7

\section{Risk of bias}

Bias Authors' judgement Support for judgement

Allocation concealment? Low risk A-Adequate

Pearson 1988b

Study design: RCT
Unit of allocation: Patient
Unit of analysis: Patient
Power calculation: Not done
Concealment*: Done. Randomisation from opaque sealed envelopes opened after consent
Follow-up*: $96 \%$
Blinded assessment*: Done for lenght of stay and discharge destination. Not done for functional sta-
tus.
Baseline*: Significant difference in Clifton Assessment Procedures for the Elderly score favours inter-
vention
Reliable outcomes*: Done for length of stay and discharge destinatination. Not clear for functional sta-
tus.
Contamination*. Unlikely - control patients not exposed to NLU
Intention to treat analysis*: Not done (treatment group patients dropped if not transferred to NLU)


Pearson 1988b (Continued)

Participants
Patients post acute admission following stroke, fractured neck of femur or amputation of lower limb assessed as being medically stable and having a remediable nursing need. Mean stay in acute care 10.8 days (treatment group only) Mean age 80.7 years $61 \%$ female.

Treatment 87

Control 77

$96 \%$ of patients randomised were followed up to discharge

Interventions

Unit / setting: 16 bedded unit in acute district general hospital

Care management: Patients assessed by senior nurse practitioner and medical officer (both had power of veto) care managed and planned by primary nurses.

Nursing Team: 10.6 whole time equivalent qualified (RN) nurses and 5.3 Whole Time Equivalents ward orderly (nursing aides)

MD team: Social worker, physiotherapist occupational therapy and Dr available on referral in advisory capacity and through weekly team meeting. A part time activity co-coordinator worked as a member of the team.

Education / preparation for staff:

Other: Environment attempted to create a 'homely' atmosphere with carpets, a bar, dining table piano etc in a large sitting room. Nurses did not wear uniform

Control: usual care in medically managed acute wards and community hospitals

\begin{tabular}{ll}
\hline Outcomes & Length of stay \\
& Place of discharge \\
& Mortality \\
& Dependency \\
& Life satisfaction \\
Nursing care quality & Cost of nursing staff
\end{tabular}

Notes Quality score 3/7

\section{Risk of bias}

Bias Authors' judgement Support for judgement

Allocation concealment? Low risk Adequate

Steiner 2001

Study design: RCT using 'Zellen's design' with single consent
Unit of allocation: Patient
Unit of analysis: Patient
Power calculation: Done - powered to detect medium or smaller effect sizes
Concealment*: Not done. Randomisation prior to consent from opaque sealed envelope
Follow-up*: $98 \%$ of randomised patients followed up.
Blinded assessment*: Done for lenght of stay and discharge destination. Not clear for data extracted
from charts.
Baseline ${ }^{\star}:$ No substantial differences at baseline.
Reliable outcomes ${ }^{\star}:$ Done for length of stay and discharge destinatination. Not clear for data extracted
from charts
Contamination ${ }^{\star}$. Unlikely - control patients not exposed to NLU
Intention to treat analysis ${ }^{\star}:$ Analysis done on intention to treat basis

Participants

Post-acute patients referred from acute medical wards of tertiary teaching hospital, assessed as being medically stable. Time from initial admission not specified. Most frequent diagnoses respiratory, cardiovascular (including stroke) and gastrointestinal 
Steiner 2001 (Continued)

Treatment 119 mean age $72.2,49 \%$ female

Control 121 mean age $69.3,60 \%$ female

$98 \%$ of patients randomised followed up to discharge for main outcomes (Length of Stay / mortality)

Interventions

Unit / setting: 10 nurse managed beds in 16 bedded on a satellite site (primarily out-patient) linked to an acute teaching hospital.

Care management: Nurses assessed suitability and primary nurse leads the multi-disciplinary team.

Care planning mechanism not specified but nurses take decision to discharge.

Nursing Team: 22 nurses (whole time equivalent) 60\% qualified.

MD team: No formal medical involvement except on referral. Regular physiotherapy and occupational

therapy, other therapists available on request.

Education / preparation for staff: No special training given / required

Other: Open visiting and informal uniform for nurses to promote non clinical atmosphere

Control: Usual post acute care in hospital. Staffing ratio derived from a typical' control ward (Walsh et al 2003) .8 nurses per patient, $60 \%$ qualified (registered / licensed)

\begin{tabular}{ll}
\hline Outcomes & Length of stay \\
& Functional dependence \\
& place of discharge \\
& mortality \\
& Readmission \\
& Complications \\
& Resource use \\
& Quality of care \\
\hline Notes & Quality score $4 / 7$
\end{tabular}

\section{Risk of bias}

\begin{tabular}{lll}
\hline Bias & Authors' judgement & Support for judgement \\
\hline Allocation concealment? & Unclear risk & B - Unclear \\
\hline
\end{tabular}

Walsh 1999

$\begin{array}{ll}\text { Methods } & \text { Study design: RCT } \\ \text { Unit of allocation: Patient } \\ \text { Unit of analysis: Patient } \\ \text { Power calculation: Not done } \\ \text { Concealment*: Done. Randomisation from opaque sealed envelopes opened after consent } \\ \text { Follow-up*: } 100 \% \text {. } \\ \text { Blinded assessment*: Done for lenght of stay and discharge destination. Not done for functional sta- } \\ \text { tus. } \\ \text { Baseline*: Not clear. Reported no significant differences at baseline but data not given and power low } \\ \text { Reliable outcomes*: Done for length of stay and discharge destinatination. Not clear for functional sta- } \\ \text { tus. } \\ \text { Contamination*. Unlikely - control patients not exposed to NLU } \\ \text { Intention to treat analysis*: Done }\end{array}$
Participants Post-acute patients referred from acute medical wards of tertiary teaching hospital, assessed as being medically stable. Time from initial admission not specified. 9 patients in treatment group, 8 control. No other detail given.
Interventions
Unit / setting: 10 bedded unit on a satellite site (primarily out-patient) linked to an acute teaching hos- pital.


Walsh 1999 (Continued)

Care management: Nurses assessed suitability and primary nurse leads the multi-disciplinary team.

Care planning mechanism not specified but nurses take decision to discharge.

Nursing Team: 22 nurses (whole time equivalent) $60 \%$ qualified).

MD team: No formal medical involvement except on referral. Regular physiotherapy and occupational

therapy, other therapists available on request.

Education / preparation for staff: No special training given / required

Other: Open visiting and informal uniform for nurses to promote non clinical atmosphere

Control: Usual post acute care in hospital

\begin{tabular}{|c|c|c|}
\hline Outcomes & $\begin{array}{l}\text { Length of stay } \\
\text { Functional dependence } \\
\text { place of discharge } \\
\text { mortality }\end{array}$ & \\
\hline Notes & Quality score 4/7 & \\
\hline Risk of bias & & \\
\hline Bias & Authors' judgement & Support for judgement \\
\hline Allocation concealment? & Low risk & A - Adequate \\
\hline
\end{tabular}

*Items that contribute to quality score if 'done'. Overall rating for follow up based on over $80 \%$ follow up for lenght of stay, place of discharge and functional status at discharge for live discharges - lowest figure used.

Characteristics of excluded studies [ordered by study ID]

\begin{tabular}{ll}
\hline Study & Reason for exclusion \\
\hline Bachmann 1987 & $\begin{array}{l}\text { Intervention comprises general development of services for older people. Fails to meet operational } \\
\text { definition of nurse-managed care in terms of admission and discharge rights although nurses are } \\
\text { more actively involved in care }\end{array}$ \\
\hline
\end{tabular}

\begin{tabular}{ll}
\hline Barrett 2001 & Descriptive data only. No comparison group \\
\hline Bond 1989 & Intervention exclusively long term care \\
\hline Burl 1998 & Intervention exclusively long term care. Joint medical / nurse practitioner management of care \\
\hline Crotty 2005 & $\begin{array}{l}\text { Care targetted exclusively at those awaiting long term care placement (therefore not clearly 'in- } \\
\text { termediate care') and does not appear to be nurse-managed care but a medically led team with a } \\
\text { nurse-coordinator. }\end{array}$ \\
\hline Kane 1989 & Intervention primarily in long term care. \\
\hline Landefeld 1995 & $\begin{array}{l}\text { Intervention comprises general development of services for older people. Fails to meet operational } \\
\text { definition of nurse-managed care in terms of admission and dischage rights although nurses are } \\
\text { more actively involved in care management. }\end{array}$ \\
\hline
\end{tabular}

Michael $2004 \quad$ Study is not a CBA and two groups are not comparable.

\begin{tabular}{ll}
\hline Mullen 1995 & Descriptive data only. No comparison group. \\
\hline Nelson 1984 & Descriptive data and change in patient condition only reported. No comparison group. \\
\hline
\end{tabular}




\begin{tabular}{ll}
\hline Study & Reason for exclusion \\
\hline Pioro 2001 & $\begin{array}{l}\text { Nurse practitioners substitute for house staff not consultant / attending in care management. Fails } \\
\text { to meet operational definition of nurse-managed care in terms of admission and discharge rights } \\
\text { although nurses are more actively involved in care management. }\end{array}$
\end{tabular}

\begin{tabular}{ll}
\hline Shepperdson 2001 & Not a nurse-led unit as nurses could only admit to 2/16 beds \\
\hline Sitzia 1998 & Descriptive data and change in patient condition only reported. No comparison group. \\
\hline von Sternberg 1997 & $\begin{array}{l}\text { Programme of sub-acute care involving nurse practioners in care management but care team is ex- } \\
\text { plicitly led by a geriatrician. }\end{array}$ \\
\hline Wilce 1988 & Purely descriptive account of an intervention. Nurse leadership unclear. \\
\hline
\end{tabular}

\section{DATA AND ANALYSES}

\section{Comparison 1. NLU vs general inpatient care}

\begin{tabular}{|c|c|c|c|c|}
\hline Outcome or subgroup title & $\begin{array}{l}\text { No. of } \\
\text { studies }\end{array}$ & $\begin{array}{l}\text { No. of } \\
\text { partici- } \\
\text { pants }\end{array}$ & Statistical method & Effect size \\
\hline 1 Inpatient mortality & 7 & 953 & Odds Ratio (M-H, Random, 95\% Cl) & $1.10[0.56,2.16]$ \\
\hline 1.1 Stronger studies & 4 & 607 & Odds Ratio (M-H, Random, 95\% Cl) & $1.52[0.86,2.68]$ \\
\hline 1.2 Weaker studies & 3 & 346 & Odds Ratio (M-H, Random, 95\% Cl) & $0.68[0.13,3.46]$ \\
\hline $\begin{array}{l}2 \text { Early post discharge death (4-6 } \\
\text { weeks) }\end{array}$ & 4 & 892 & Odds Ratio (M-H, Random, 95\% Cl) & $0.63[0.25,1.62]$ \\
\hline 2.1 Stronger studies & 1 & 153 & Odds Ratio (M-H, Random, $95 \% \mathrm{Cl})$ & $0.44[0.08,2.49]$ \\
\hline 2.2 Weaker studies & 3 & 739 & Odds Ratio (M-H, Random, $95 \% \mathrm{Cl})$ & $0.74[0.24,2.24]$ \\
\hline $\begin{array}{l}3 \text { Mortality within } 3 \text { months of admis- } \\
\text { sion ( } 12 \text { weeks / } 90 \text { days) }\end{array}$ & 3 & 885 & Odds Ratio (M-H, Random, 95\% Cl) & $1.60[0.93,2.75]$ \\
\hline 3.1 Stronger studies & 2 & 352 & Odds Ratio (M-H, Random, $95 \% \mathrm{Cl})$ & $1.52[0.82,2.82]$ \\
\hline 3.2 Weaker studies & 1 & 533 & Odds Ratio (M-H, Random, 95\% Cl) & $1.88[0.61,5.80]$ \\
\hline $\begin{array}{l}4 \text { Mortality within } 6 \text { months of admis- } \\
\text { sion ( } 24 \text { weeks / } 180 \text { days) }\end{array}$ & 3 & 946 & Odds Ratio (M-H, Random, $95 \% \mathrm{Cl})$ & $0.96[0.63,1.47]$ \\
\hline 4.1 Stronger studies & 2 & 413 & Odds Ratio (M-H, Random, 95\% Cl) & $0.95[0.58,1.56]$ \\
\hline 4.2 Weaker studies & 1 & 533 & Odds Ratio (M-H, Random, 95\% Cl) & $1.00[0.46,2.20]$ \\
\hline $\begin{array}{l}5 \text { Mortality to longest follow up (within } \\
6 \text { months) }\end{array}$ & 6 & 1350 & Odds Ratio (M-H, Random, $95 \% \mathrm{Cl})$ & $0.92[0.65,1.29]$ \\
\hline
\end{tabular}




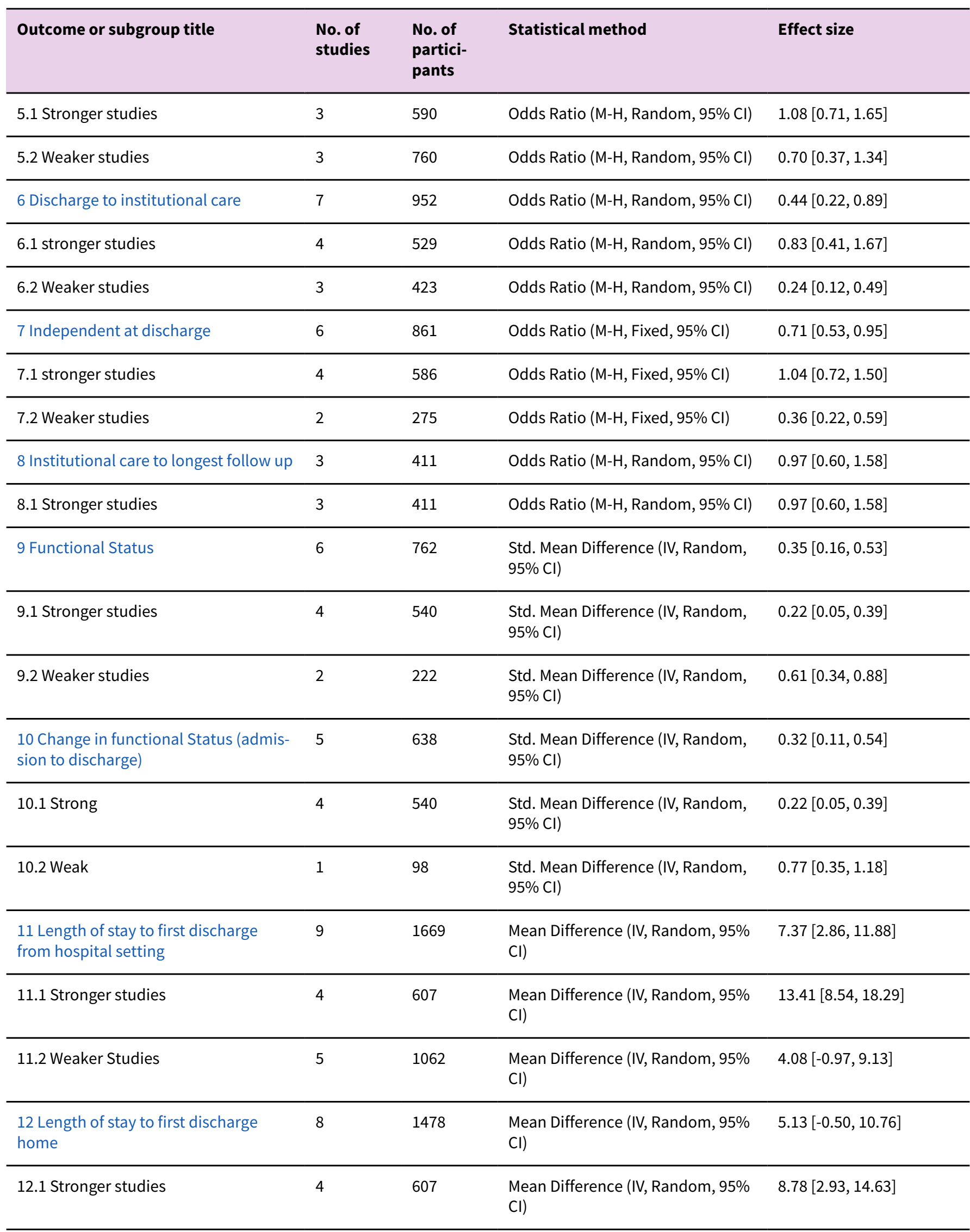




\begin{tabular}{|c|c|c|c|c|}
\hline Outcome or subgroup title & $\begin{array}{l}\text { No. of } \\
\text { studies }\end{array}$ & $\begin{array}{l}\text { No. of } \\
\text { partici- } \\
\text { pants }\end{array}$ & Statistical method & Effect size \\
\hline 12.2 Weaker Studies & 4 & 871 & $\begin{array}{l}\text { Mean Difference (IV, Random, 95\% } \\
\mathrm{CI})\end{array}$ & $-1.37[-13.52,10.79]$ \\
\hline 13 Early readmission (within 30 days) & 5 & 1126 & Odds Ratio (M-H, Random, $95 \% \mathrm{Cl})$ & $0.52[0.34,0.80]$ \\
\hline 13.1 Stronger studies & 3 & 493 & Odds Ratio (M-H, Random, 95\% Cl) & $0.63[0.36,1.12]$ \\
\hline 13.2 Weaker studies & 2 & 633 & Odds Ratio (M-H, Random, 95\% Cl) & $0.40[0.21,0.76]$ \\
\hline 14 Quality of life / health status & 5 & 448 & $\begin{array}{l}\text { Std. Mean Difference (IV, Random, } \\
95 \% \mathrm{Cl} \text { ) }\end{array}$ & $0.28[0.09,0.48]$ \\
\hline 14.1 Stronger studies & 2 & 238 & $\begin{array}{l}\text { Std. Mean Difference (IV, Random, } \\
95 \% \mathrm{Cl} \text { ) }\end{array}$ & $0.33[-0.01,0.67]$ \\
\hline 14.2 Weaker studies & 3 & 210 & $\begin{array}{l}\text { Std. Mean Difference (IV, Random, } \\
95 \% \mathrm{CI} \text { ) }\end{array}$ & $0.22[-0.07,0.51]$ \\
\hline $\begin{array}{l}15 \text { Quality of life / health status change } \\
\text { scores only }\end{array}$ & 3 & 275 & $\begin{array}{l}\text { Std. Mean Difference (IV, Random, } \\
95 \% \mathrm{CI})\end{array}$ & $0.22[-0.15,0.59]$ \\
\hline 15.1 Stronger studies & 2 & 238 & $\begin{array}{l}\text { Std. Mean Difference (IV, Random, } \\
95 \% \mathrm{CI})\end{array}$ & $0.33[-0.01,0.67]$ \\
\hline 15.2 Weaker studies & 1 & 37 & $\begin{array}{l}\text { Std. Mean Difference (IV, Random, } \\
95 \% \mathrm{Cl})\end{array}$ & $-0.30[-1.12,0.53]$ \\
\hline 16 Psychological wellbeing & 3 & 280 & $\begin{array}{l}\text { Std. Mean Difference (IV, Random, } \\
95 \% \mathrm{Cl})\end{array}$ & $0.36[-0.03,0.74]$ \\
\hline 16.1 Stronger studies & 2 & 244 & $\begin{array}{l}\text { Std. Mean Difference (IV, Random, } \\
95 \% \mathrm{CI})\end{array}$ & $0.25[-0.03,0.52]$ \\
\hline 16.2 Weaker studies & 1 & 36 & $\begin{array}{l}\text { Std. Mean Difference (IV, Random, } \\
95 \% \mathrm{Cl} \text { ) }\end{array}$ & $1.04[0.17,1.90]$ \\
\hline 17 Satisfaction & 4 & 335 & $\begin{array}{l}\text { Std. Mean Difference (IV, Random, } \\
95 \% \mathrm{CI} \text { ) }\end{array}$ & $0.22[-0.03,0.46]$ \\
\hline 17.1 Stronger studies & 2 & 175 & $\begin{array}{l}\text { Std. Mean Difference (IV, Random, } \\
95 \% \mathrm{CI} \text { ) }\end{array}$ & $0.19[-0.11,0.48]$ \\
\hline 17.2 Weaker Studies & 2 & 160 & $\begin{array}{l}\text { Std. Mean Difference (IV, Random, } \\
95 \% \mathrm{CI} \text { ) }\end{array}$ & $0.29[-0.15,0.72]$ \\
\hline
\end{tabular}

Analysis 1.1. Comparison 1 NLU vs general inpatient care, Outcome 1 Inpatient mortality.

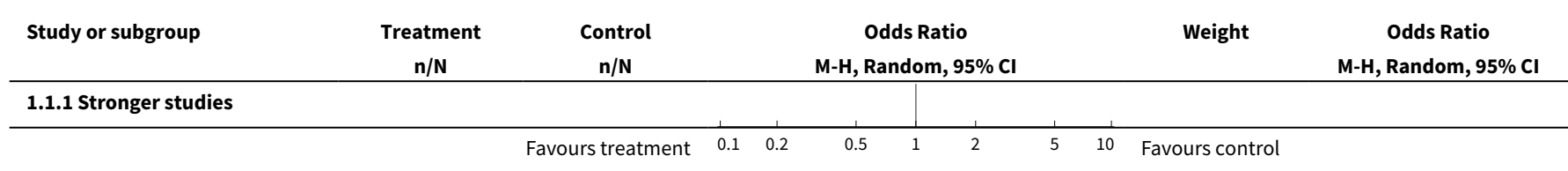




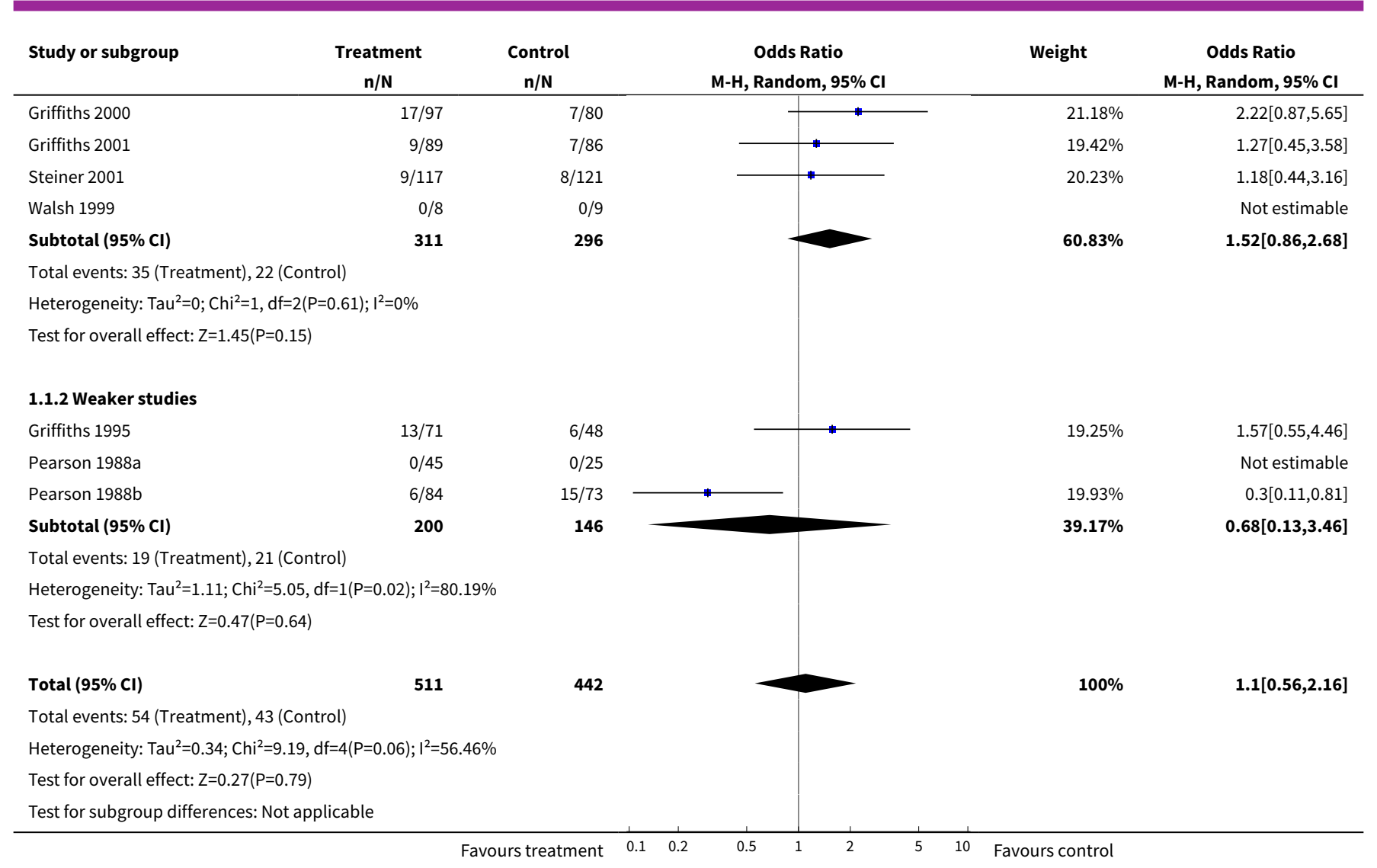

Analysis 1.2. Comparison 1 NLU vs general inpatient care, Outcome 2 Early post discharge death (4-6 weeks).

\begin{tabular}{|c|c|c|c|c|c|}
\hline Study or subgroup & $\begin{array}{c}\text { Treatment } \\
\mathrm{n} / \mathrm{N} \\
\end{array}$ & $\begin{array}{c}\text { Control } \\
\mathrm{n} / \mathrm{N}\end{array}$ & $\begin{array}{c}\text { Odds Ratio } \\
\text { M-H, Random, } 95 \% \mathrm{Cl}\end{array}$ & Weight & $\begin{array}{c}\text { Odds Ratio } \\
\text { M-H, Random, } 95 \% \mathrm{Cl}\end{array}$ \\
\hline \multicolumn{6}{|c|}{ 1.2.1 Stronger studies } \\
\hline Griffiths 2000 & $2 / 80$ & $4 / 73$ & $\longrightarrow$ & $29.31 \%$ & $0.44[0.08,2.49]$ \\
\hline Subtotal $(95 \% \mathrm{CI})$ & 80 & 73 & & $29.31 \%$ & $0.44[0.08,2.49]$ \\
\hline \multicolumn{6}{|c|}{ Total events: 2 (Treatment), 4 (Control) } \\
\hline \multicolumn{6}{|c|}{ Heterogeneity: Not applicable } \\
\hline \multicolumn{6}{|c|}{ Test for overall effect: $\mathrm{Z}=0.93(\mathrm{P}=0.35)$} \\
\hline \multicolumn{6}{|l|}{ 1.2.2 Weaker studies } \\
\hline Pearson 1988b & $4 / 78$ & $3 / 58$ & & $37.05 \%$ & $0.99[0.21,4.61]$ \\
\hline Hall 1975 & $2 / 349$ & $2 / 184$ & & $22.6 \%$ & $0.52[0.07,3.75]$ \\
\hline Pearson 1988a & $1 / 45$ & $1 / 25$ & & $11.04 \%$ & $0.55[0.03,9.12]$ \\
\hline Subtotal $(95 \% \mathrm{Cl})$ & 472 & 267 & & $70.69 \%$ & $0.74[0.24,2.24]$ \\
\hline \multicolumn{6}{|c|}{ Heterogeneity: $\mathrm{Tau}^{2}=0 ; \mathrm{Chi}^{2}=0.3, \mathrm{df}=2(\mathrm{P}=0.86) ; \mathrm{I}^{2}=0 \%$} \\
\hline \multicolumn{6}{|c|}{ Test for overall effect: $Z=0.54(P=0.59)$} \\
\hline Total $(95 \% \mathrm{Cl})$ & 552 & 340 & & $100 \%$ & $0.63[0.25,1.62]$ \\
\hline \multicolumn{6}{|c|}{ Total events: 9 (Treatment), 10 (Control) } \\
\hline \multicolumn{6}{|c|}{ Heterogeneity: $\operatorname{Tau}^{2}=0 ; \mathrm{Chi}^{2}=0.54, \mathrm{df}=3(\mathrm{P}=0.91) ; \mathrm{I}^{2}=0 \%$} \\
\hline Test for overall effect & & & & & \\
\hline
\end{tabular}




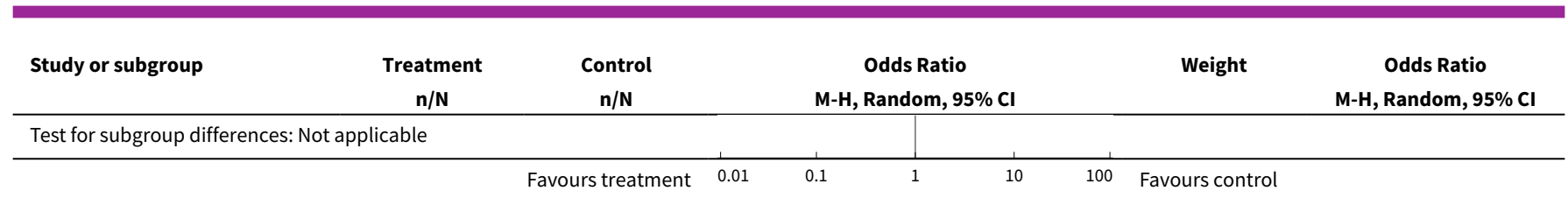

Analysis 1.3. Comparison $1 \mathrm{NLU}$ vs general inpatient care, Outcome 3 Mortality within 3 months of admission (12 weeks / 90 days).

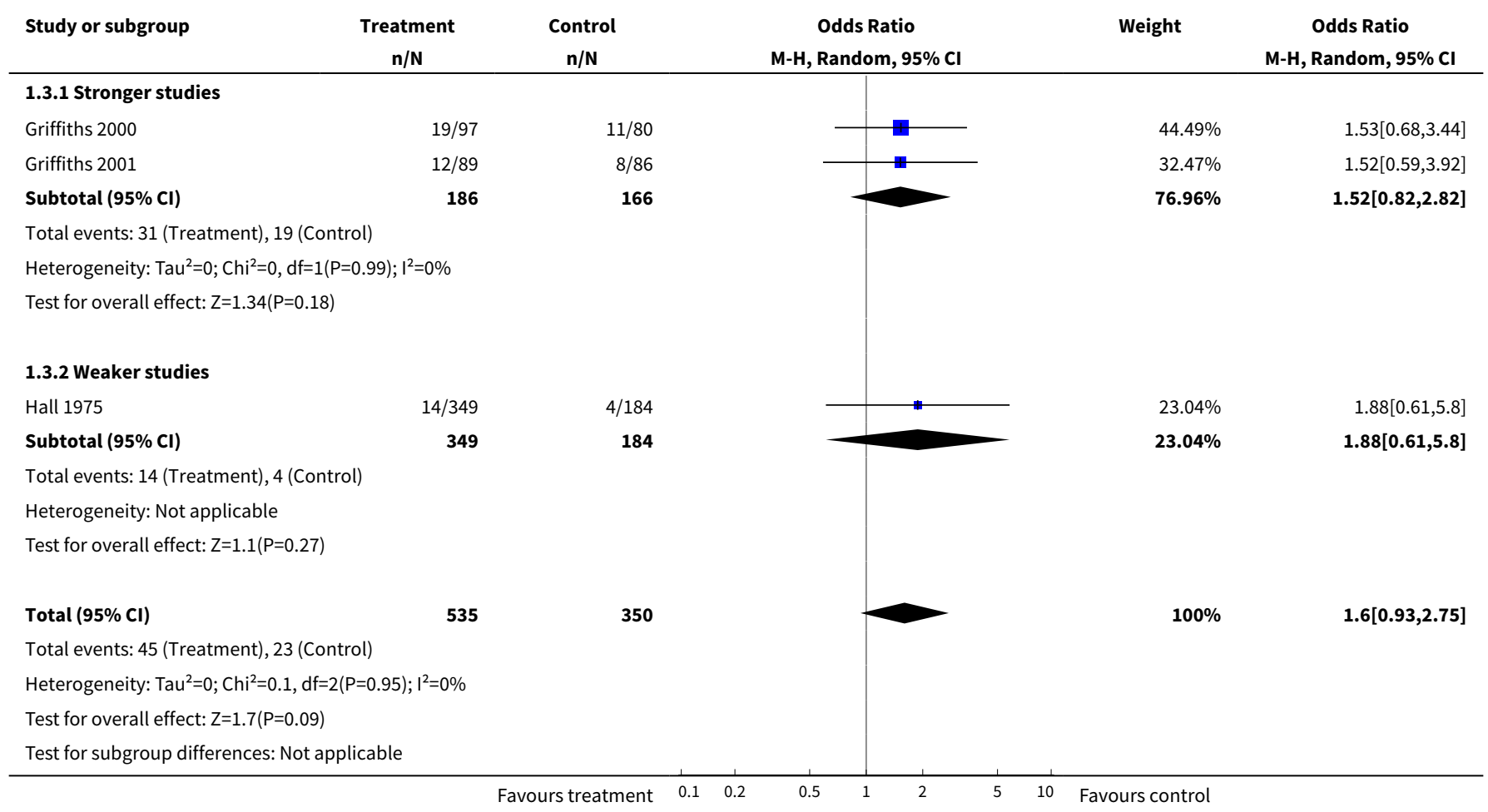

Analysis 1.4. Comparison $1 \mathrm{NLU}$ vs general inpatient care, Outcome 4 Mortality within 6 months of admission (24 weeks / 180 days).

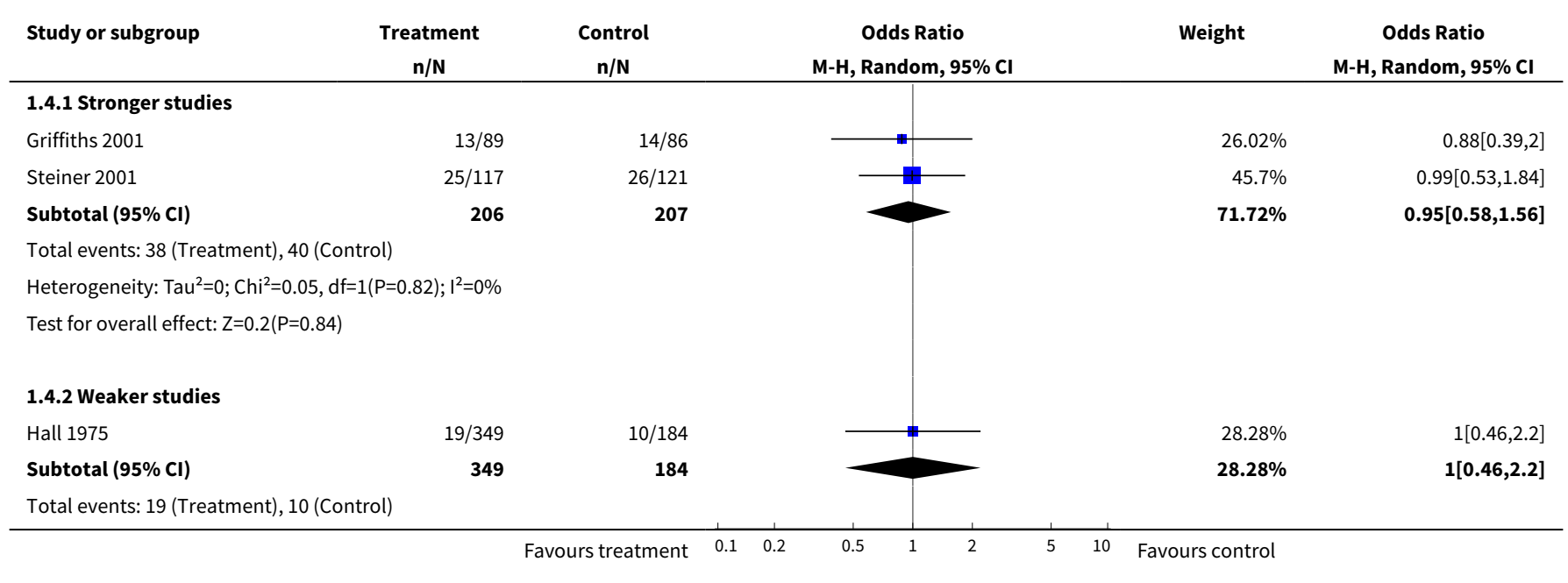




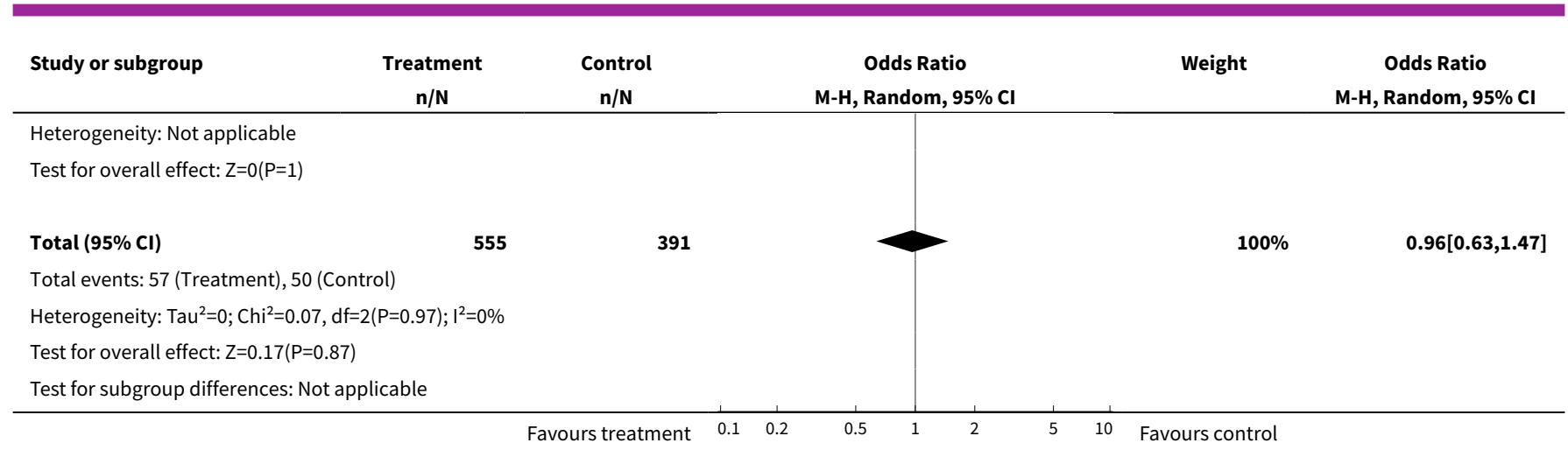

Analysis 1.5. Comparison 1 NLU vs general inpatient care, Outcome 5 Mortality to longest follow up (within 6 months).

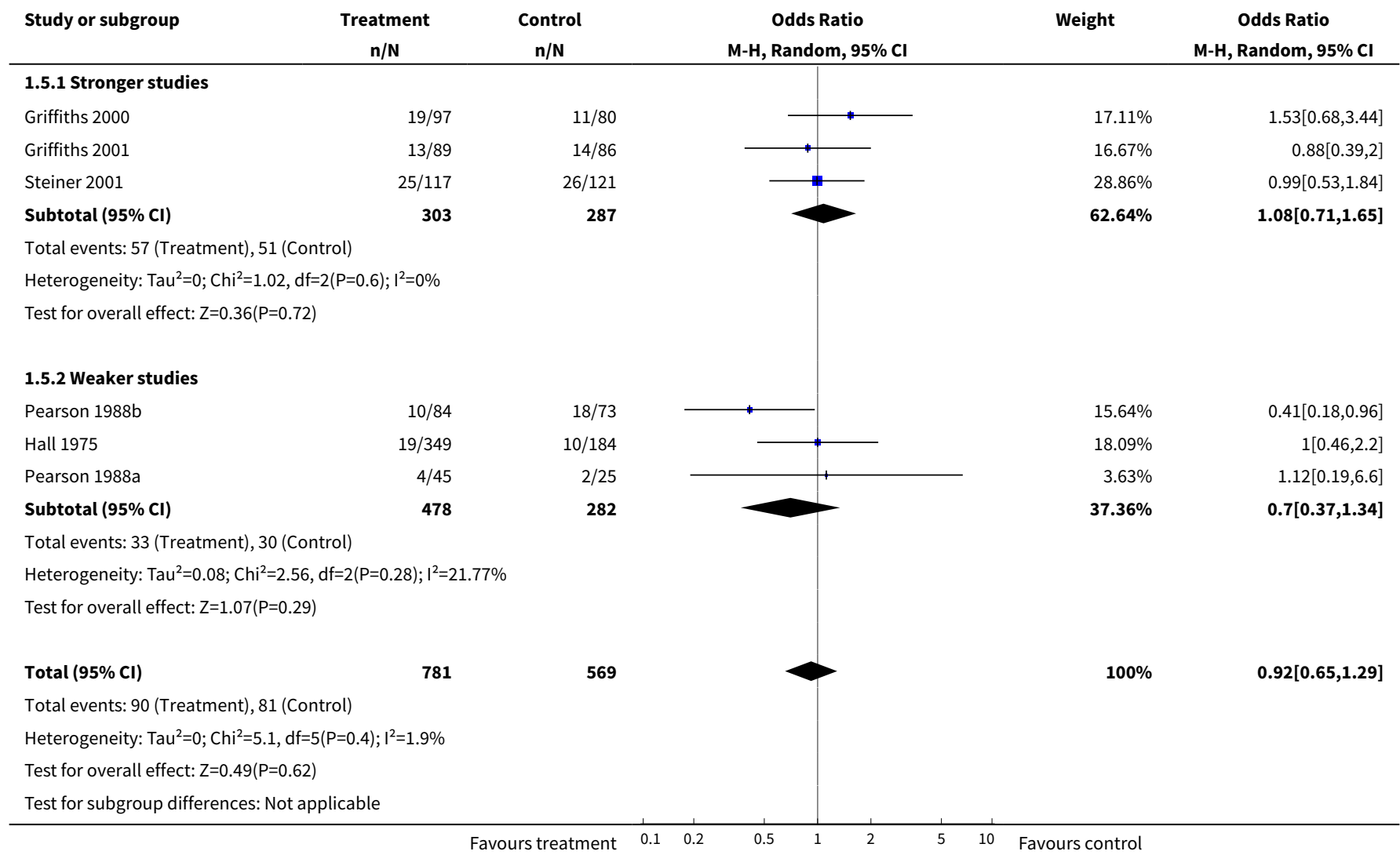

Analysis 1.6. Comparison $1 \mathrm{NLU}$ vs general inpatient care, Outcome 6 Discharge to institutional care.

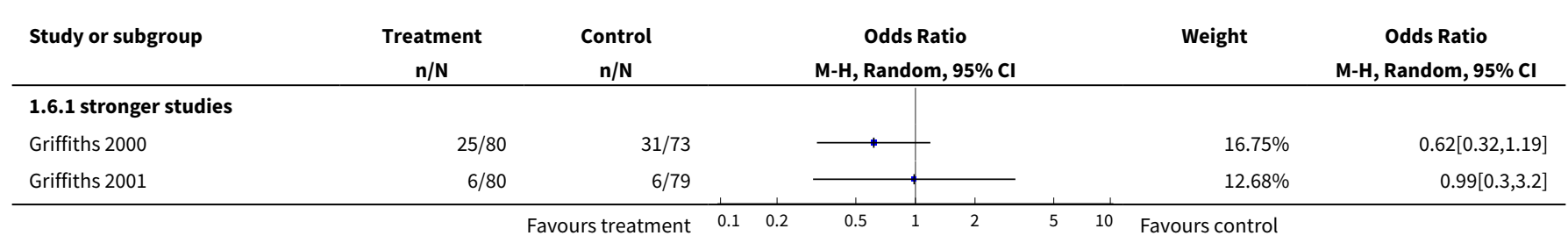




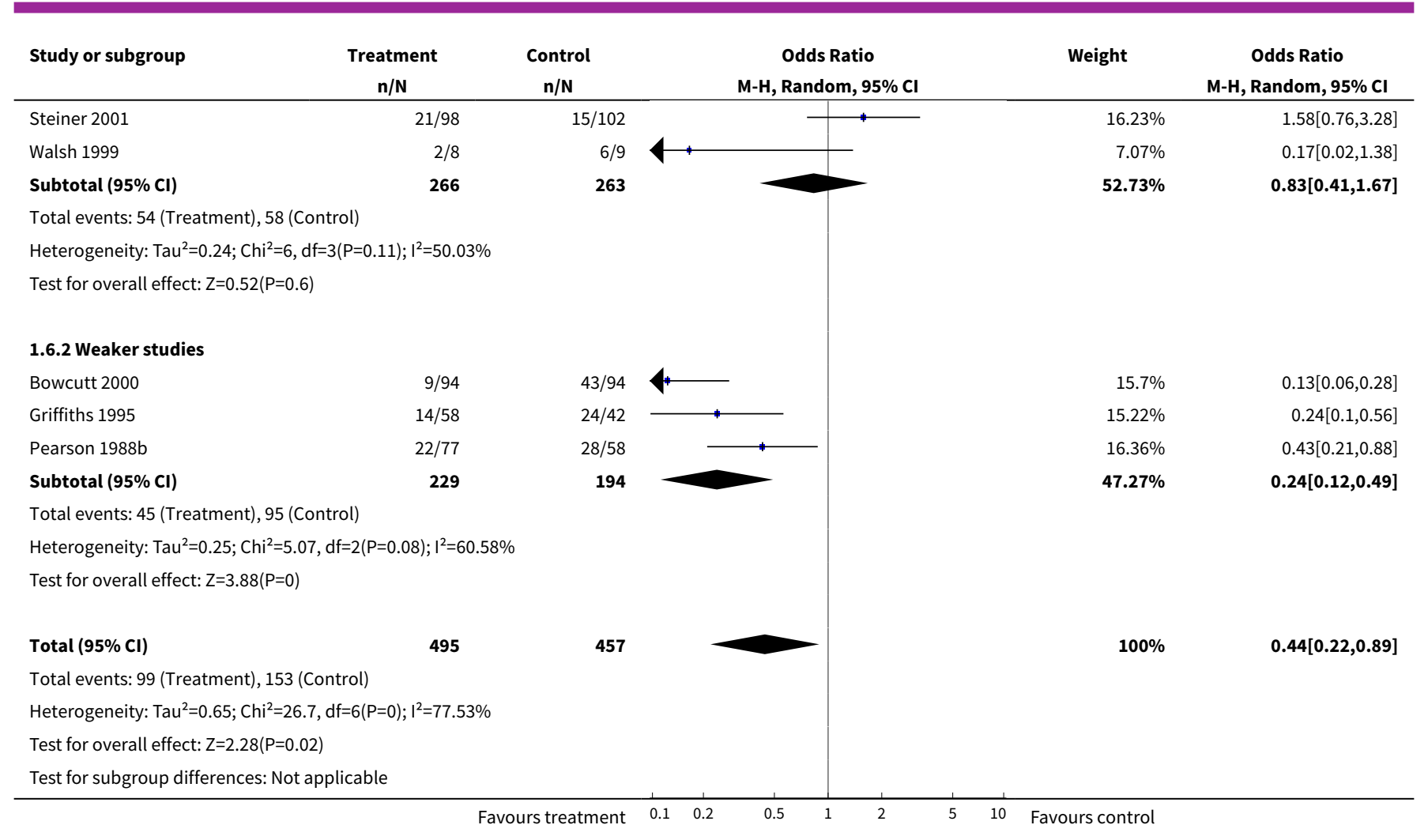

Analysis 1.7. Comparison $1 \mathrm{NLU}$ vs general inpatient care, Outcome 7 Independent at discharge.

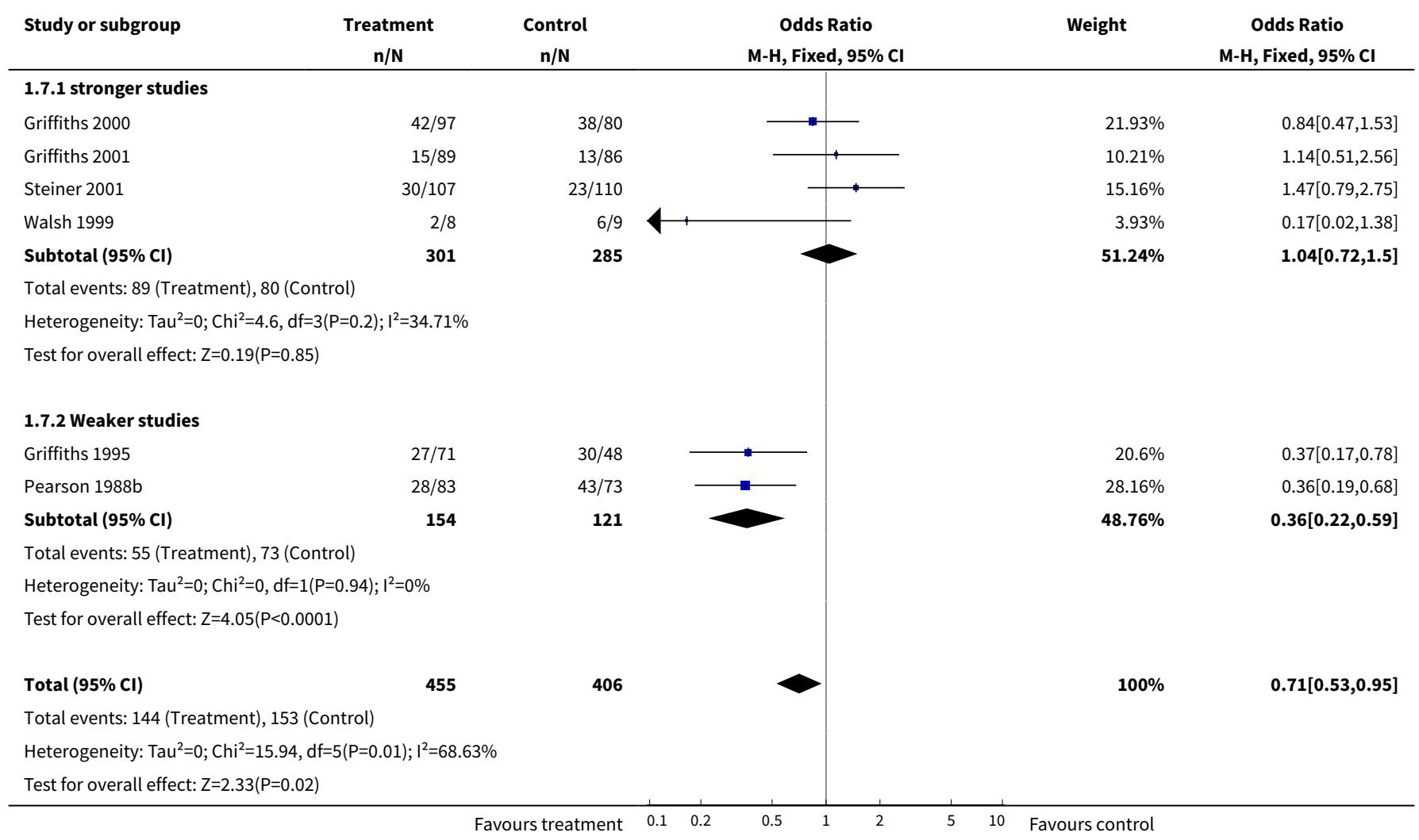




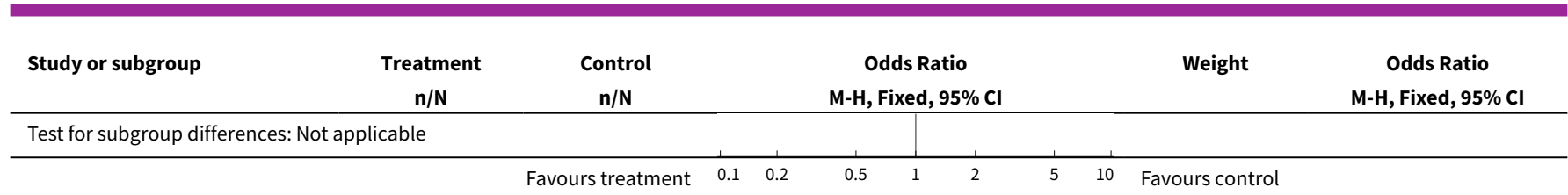

\section{Analysis 1.8. Comparison $1 \mathrm{NLU}$ vs general inpatient care, Outcome 8 Institutional care to longest follow up.}

\begin{tabular}{|c|c|c|c|c|c|}
\hline Study or subgroup & $\begin{array}{c}\text { Treatment } \\
\mathrm{n} / \mathrm{N}\end{array}$ & $\begin{array}{c}\text { Control } \\
\mathrm{n} / \mathrm{N}\end{array}$ & $\begin{array}{c}\text { Odds Ratio } \\
\text { M-H, Random, } 95 \% \mathrm{Cl}\end{array}$ & Weight & $\begin{array}{c}\text { Odds Ratio } \\
\text { M-H, Random, } 95 \% \mathrm{Cl}\end{array}$ \\
\hline \multicolumn{6}{|c|}{ 1.8.1 Stronger studies } \\
\hline Griffiths 2000 & $36 / 78$ & $39 / 69$ & r & $43.91 \%$ & $0.66[0.34,1.27]$ \\
\hline Griffiths 2001 & $13 / 71$ & $9 / 64$ & $\longrightarrow$ & $24.27 \%$ & $1.37[0.54,3.46]$ \\
\hline Steiner 2001 & $20 / 70$ & $14 / 59$ & 1 & $31.81 \%$ & $1.29[0.58,2.84]$ \\
\hline Subtotal $(95 \% \mathrm{CI})$ & 219 & 192 & & $100 \%$ & $0.97[0.6,1.58]$ \\
\hline \multicolumn{6}{|c|}{ Heterogeneity: $\mathrm{Tau}^{2}=0.03 ; \mathrm{Chi}^{2}=2.36, \mathrm{df}=2(\mathrm{P}=0.31) ; \mathrm{I}^{2}=15.38 \%$} \\
\hline \multicolumn{6}{|c|}{ Test for overall effect: $Z=0.11(P=0.91)$} \\
\hline Total $(95 \% \mathrm{Cl})$ & 219 & 192 & & $100 \%$ & $0.97[0.6,1.58]$ \\
\hline \multicolumn{6}{|c|}{ Total events: 69 (Treatment), 62 (Control) } \\
\hline \multicolumn{6}{|c|}{ Heterogeneity: $\mathrm{Tau}^{2}=0.03 ; \mathrm{Chi}^{2}=2.36, \mathrm{df}=2(\mathrm{P}=0.31) ; \mathrm{I}^{2}=15.38 \%$} \\
\hline
\end{tabular}

Analysis 1.9. Comparison 1 NLU vs general inpatient care, Outcome 9 Functional Status.

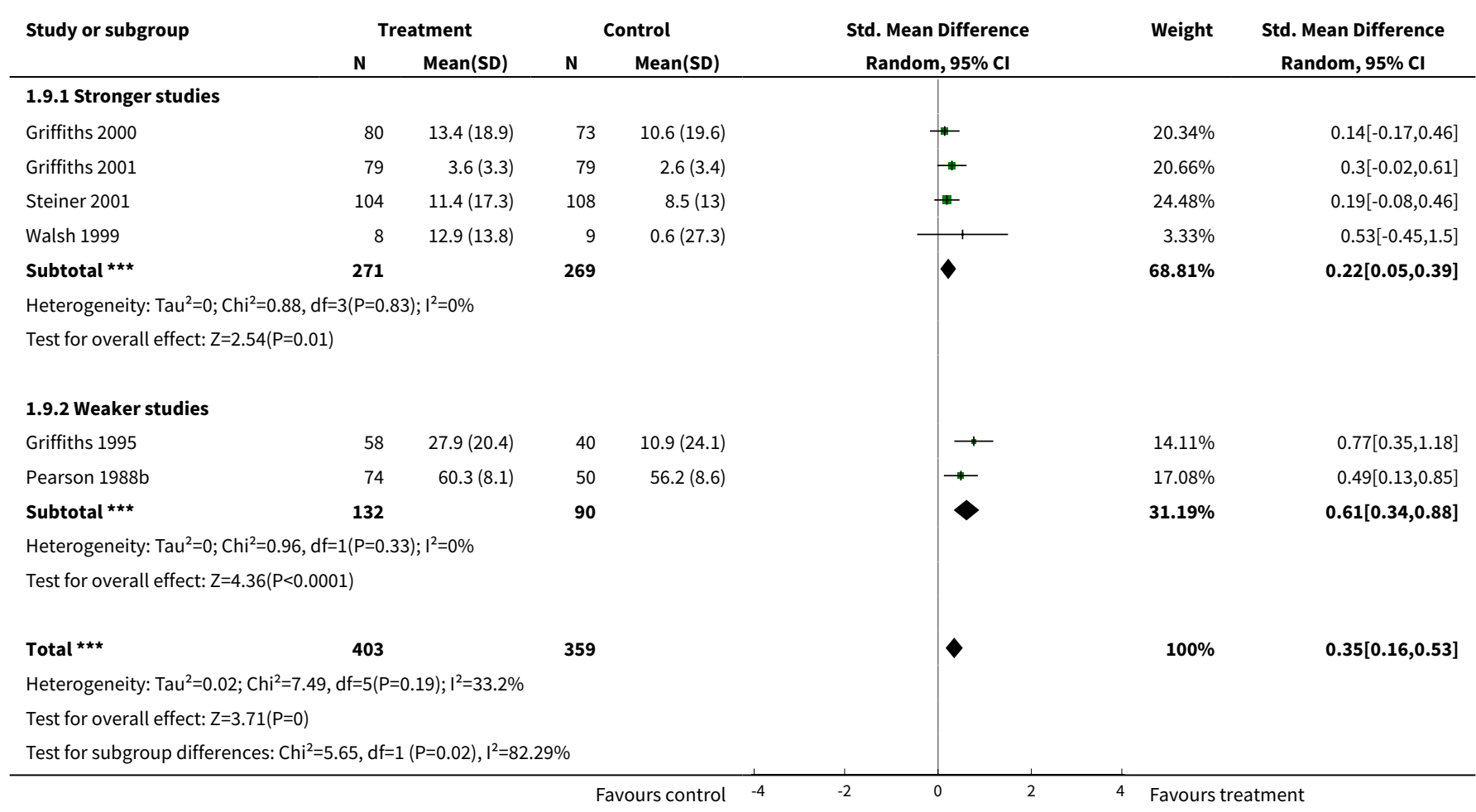


Analysis 1.10. Comparison $1 \mathrm{NLU}$ vs general inpatient care, Outcome 10 Change in functional Status (admission to discharge).

\begin{tabular}{|c|c|c|c|c|c|c|c|}
\hline \multirow[t]{2}{*}{ Study or subgroup } & \multicolumn{2}{|c|}{ Treatment } & \multicolumn{2}{|c|}{ Control } & \multirow{2}{*}{$\begin{array}{c}\text { Std. Mean Difference } \\
\text { Random, } 95 \% \mathrm{Cl}\end{array}$} & \multirow[t]{2}{*}{ Weight } & \multirow{2}{*}{$\begin{array}{c}\text { Std. Mean Difference } \\
\text { Random, } 95 \% \mathrm{Cl}\end{array}$} \\
\hline & $\mathbf{N}$ & Mean(SD) & $\mathbf{N}$ & Mean(SD) & & & \\
\hline \multicolumn{8}{|l|}{ 1.10.1 Strong } \\
\hline Griffiths 2000 & 80 & $13.4(18.9)$ & 73 & $10.6(19.6)$ & + & $24.46 \%$ & $0.14[-0.17,0.46]$ \\
\hline Griffiths 2001 & 79 & $3.6(3.3)$ & 79 & $2.6(3.4)$ & 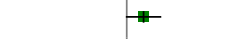 & $24.8 \%$ & $0.3[-0.02,0.61]$ \\
\hline Steiner 2001 & 104 & $11.4(17.3)$ & 108 & $8.5(13)$ & \pm & $28.8 \%$ & $0.19[-0.08,0.46]$ \\
\hline Walsh 1999 & 8 & $12.9(13.8)$ & 9 & $0.6(27.3)$ & + & $4.4 \%$ & $0.53[-0.45,1.5]$ \\
\hline \multicolumn{8}{|c|}{ Heterogeneity: $\mathrm{Tau}^{2}=0 ; \mathrm{Chi}^{2}=0.88, \mathrm{df}=3(\mathrm{P}=0.83) ; \mathrm{I}^{2}=0 \%$} \\
\hline \multicolumn{8}{|c|}{ Test for overall effect: $Z=2.54(P=0.01)$} \\
\hline \multicolumn{8}{|l|}{ 1.10.2 Weak } \\
\hline Griffiths 1995 & 58 & $27.9(20.4)$ & 40 & $10.9(24.1)$ & $\rightarrow$ & $17.54 \%$ & $0.77[0.35,1.18]$ \\
\hline Subtotal $\star \star \star$ & 58 & & 40 & & & $17.54 \%$ & $0.77[0.35,1.18]$ \\
\hline \multicolumn{8}{|c|}{ Test for overall effect: $Z=3.6(P=0)$} \\
\hline 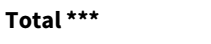 & 329 & & 309 & & $\diamond$ & $100 \%$ & $0.32[0.11,0.54]$ \\
\hline \multicolumn{8}{|c|}{ Heterogeneity: $\mathrm{Tau}^{2}=0.02 ; \mathrm{Chi}^{2}=6.57, \mathrm{df}=4(\mathrm{P}=0.16) ; \mathrm{I}^{2}=39.08 \%$} \\
\hline \multicolumn{8}{|c|}{ Test for overall effect: $Z=2.96(P=0)$} \\
\hline Test for subgroup dif & $69, \mathrm{df}=$ & $P=0.02), I^{2}=82$ & & & & & \\
\hline
\end{tabular}

Analysis 1.11. Comparison 1 NLU vs general inpatient care, Outcome 11 Length of stay to first discharge from hospital setting.

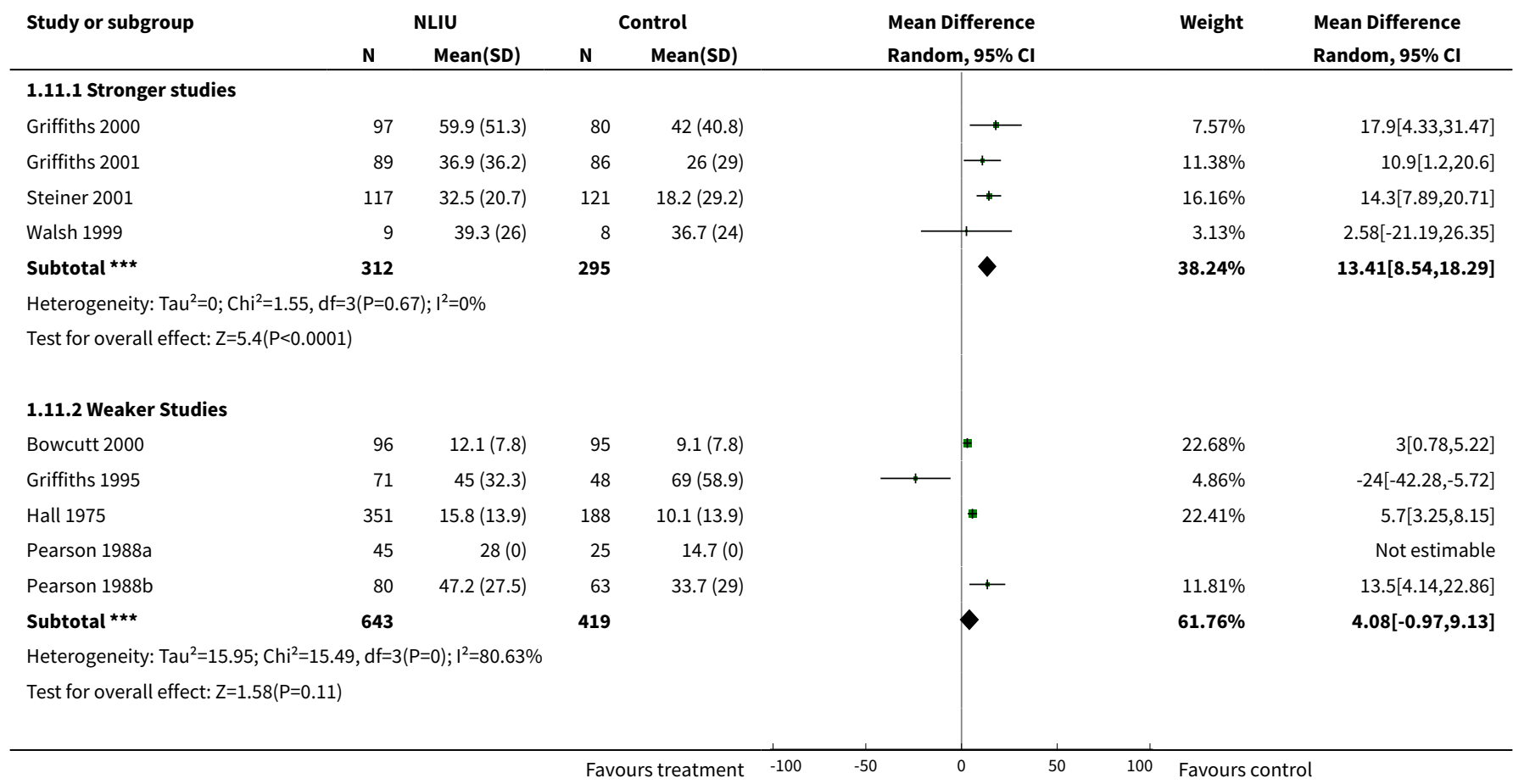




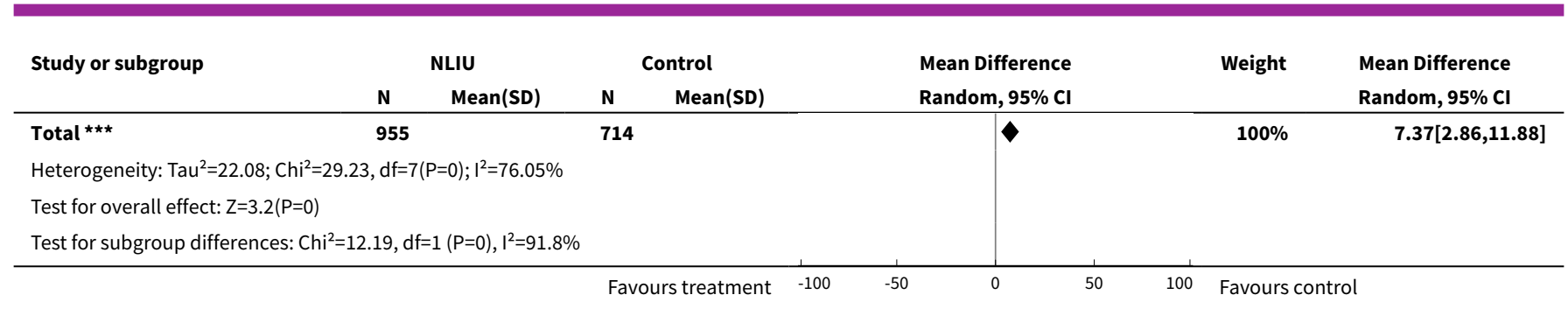

\section{Analysis 1.12. Comparison $1 \mathrm{NLU}$ vs general inpatient care, Outcome 12 Length of stay to first discharge home.}

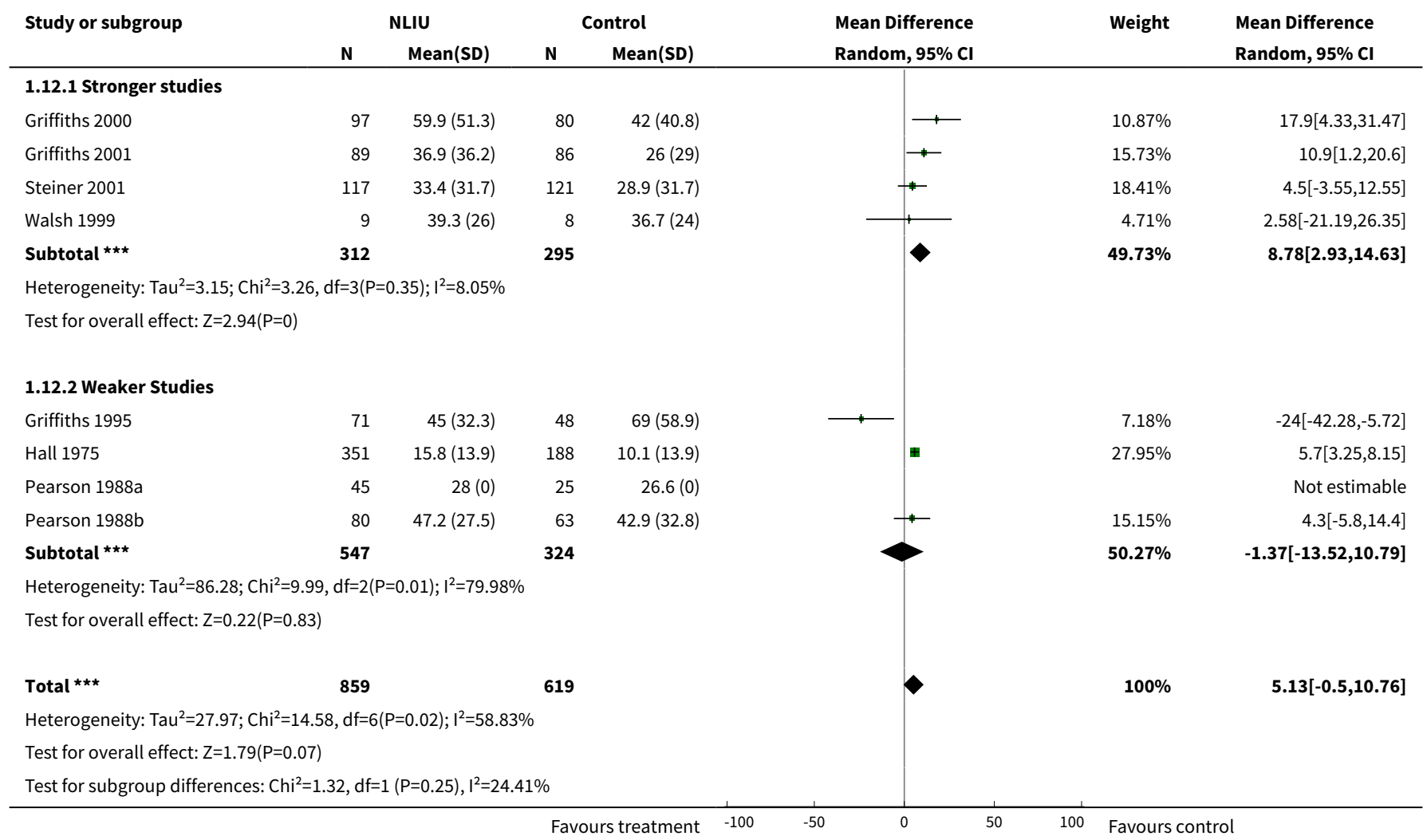

Analysis 1.13. Comparison 1 NLU vs general inpatient care, Outcome 13 Early readmission (within 30 days).

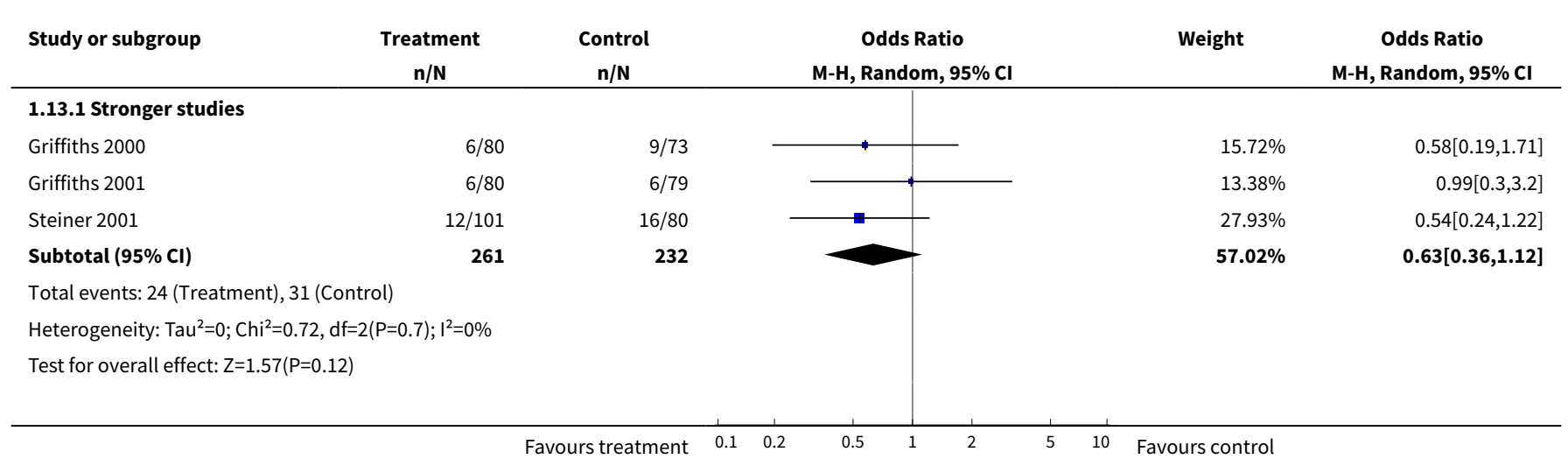




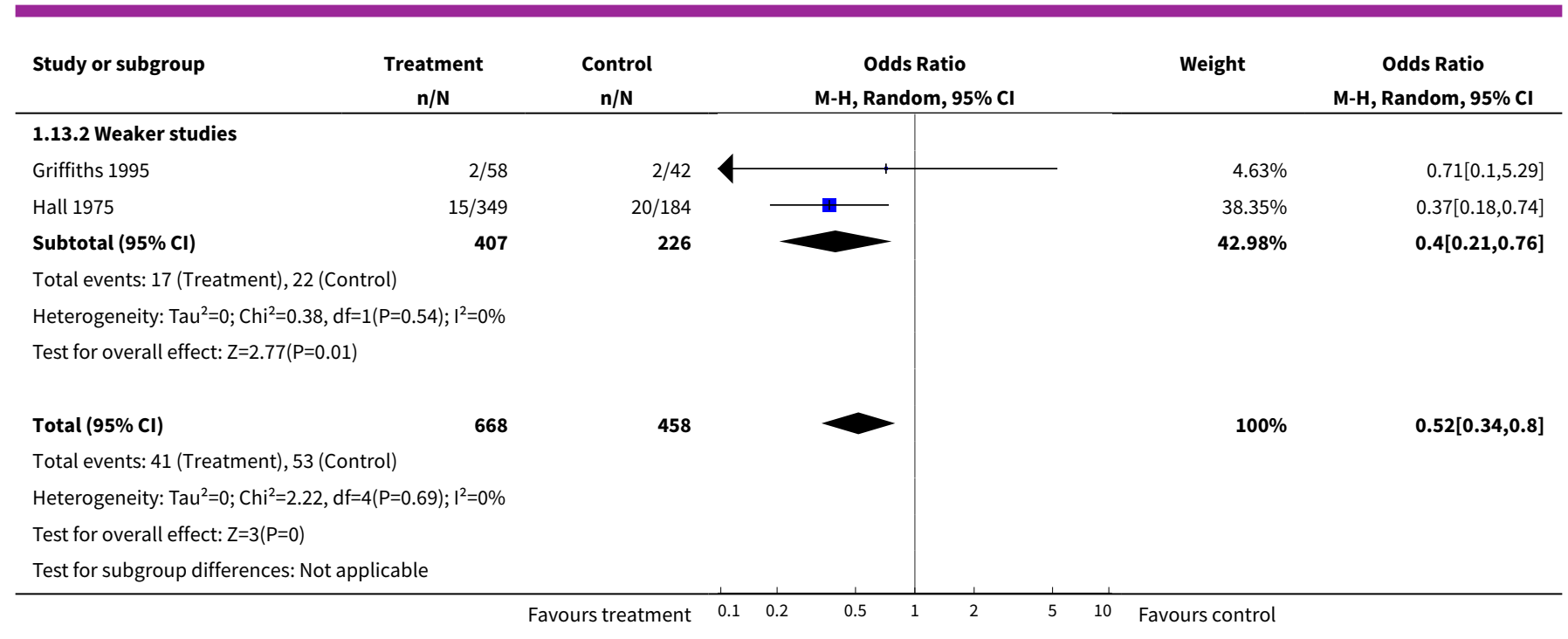

Analysis 1.14. Comparison 1 NLU vs general inpatient care, Outcome 14 Quality of life / health status.

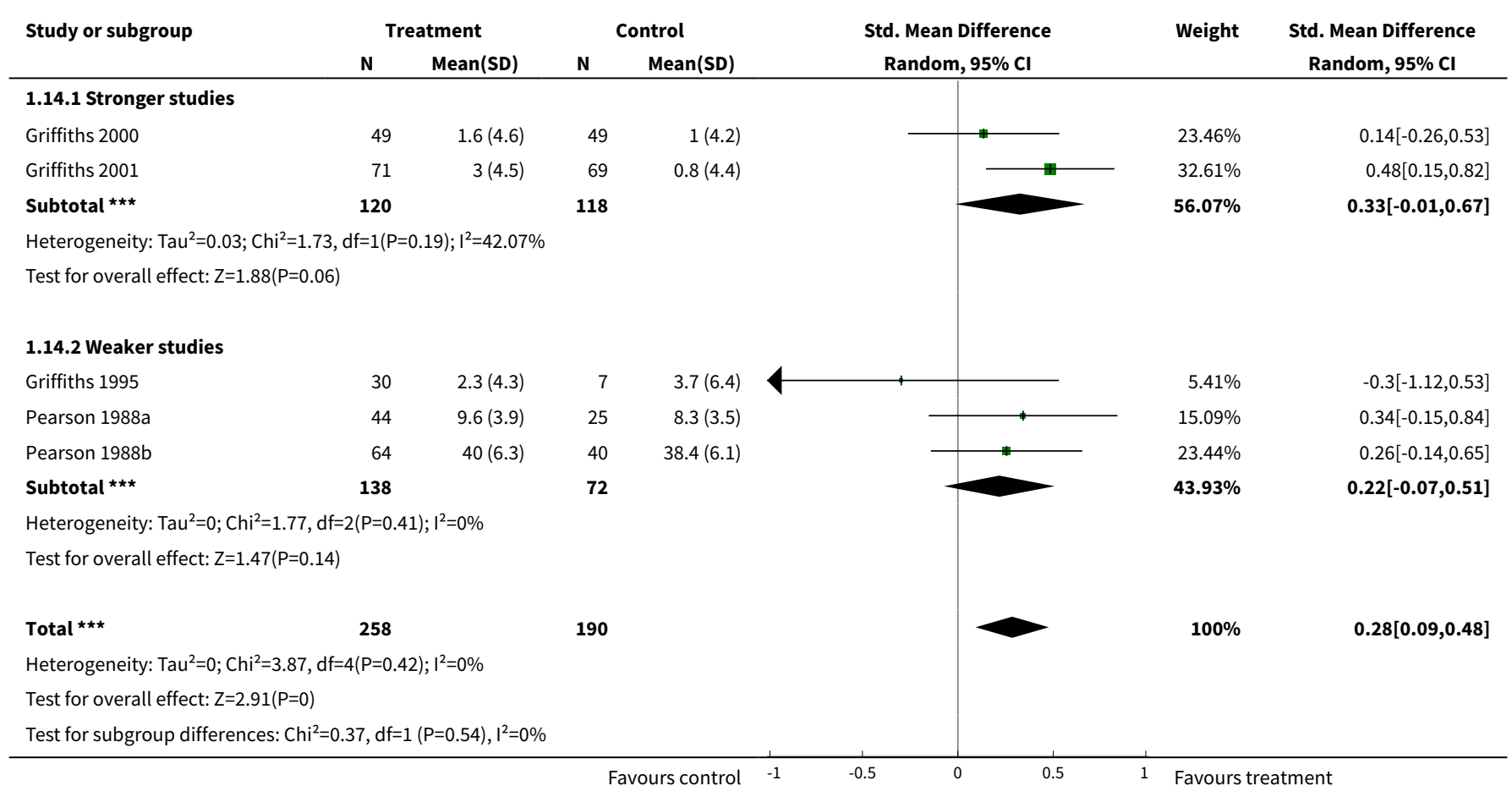

Analysis 1.15. Comparison $1 \mathrm{NLU}$ vs general inpatient care, Outcome 15 Quality of life / health status change scores only.

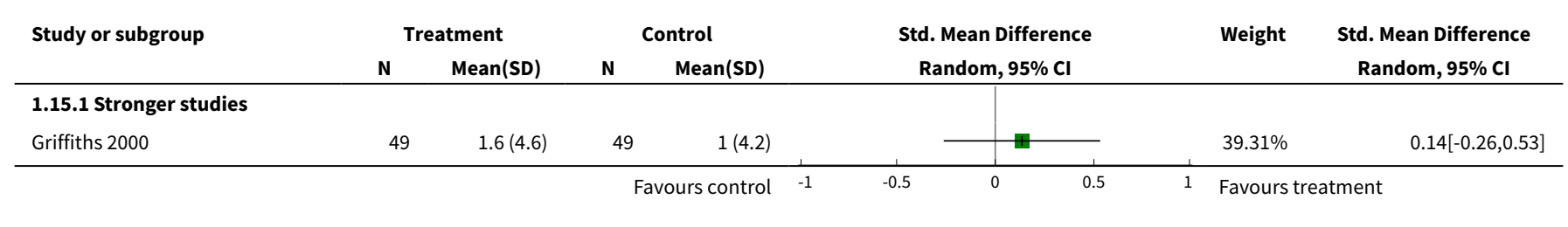




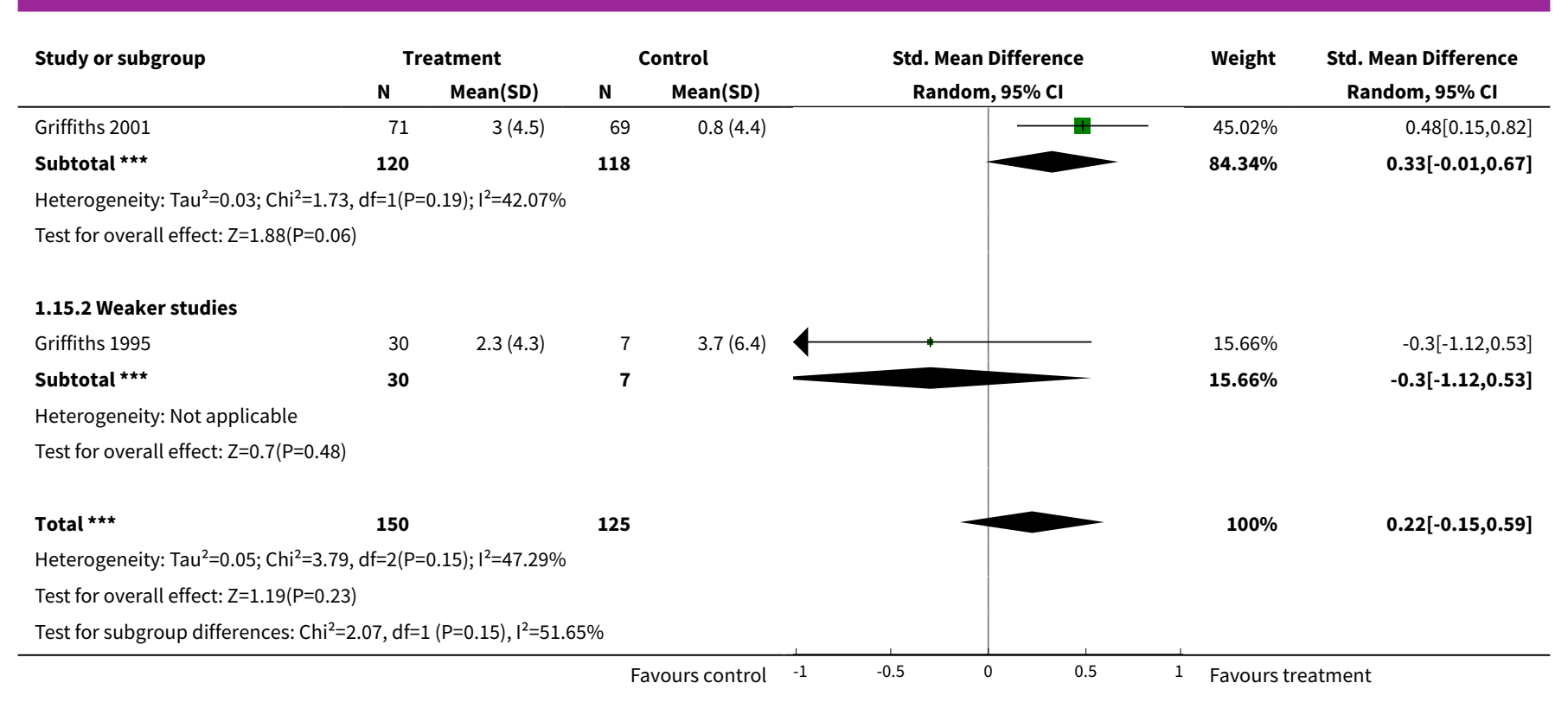

\section{Analysis 1.16. Comparison 1 NLU vs general inpatient care, Outcome 16 Psychological wellbeing.}

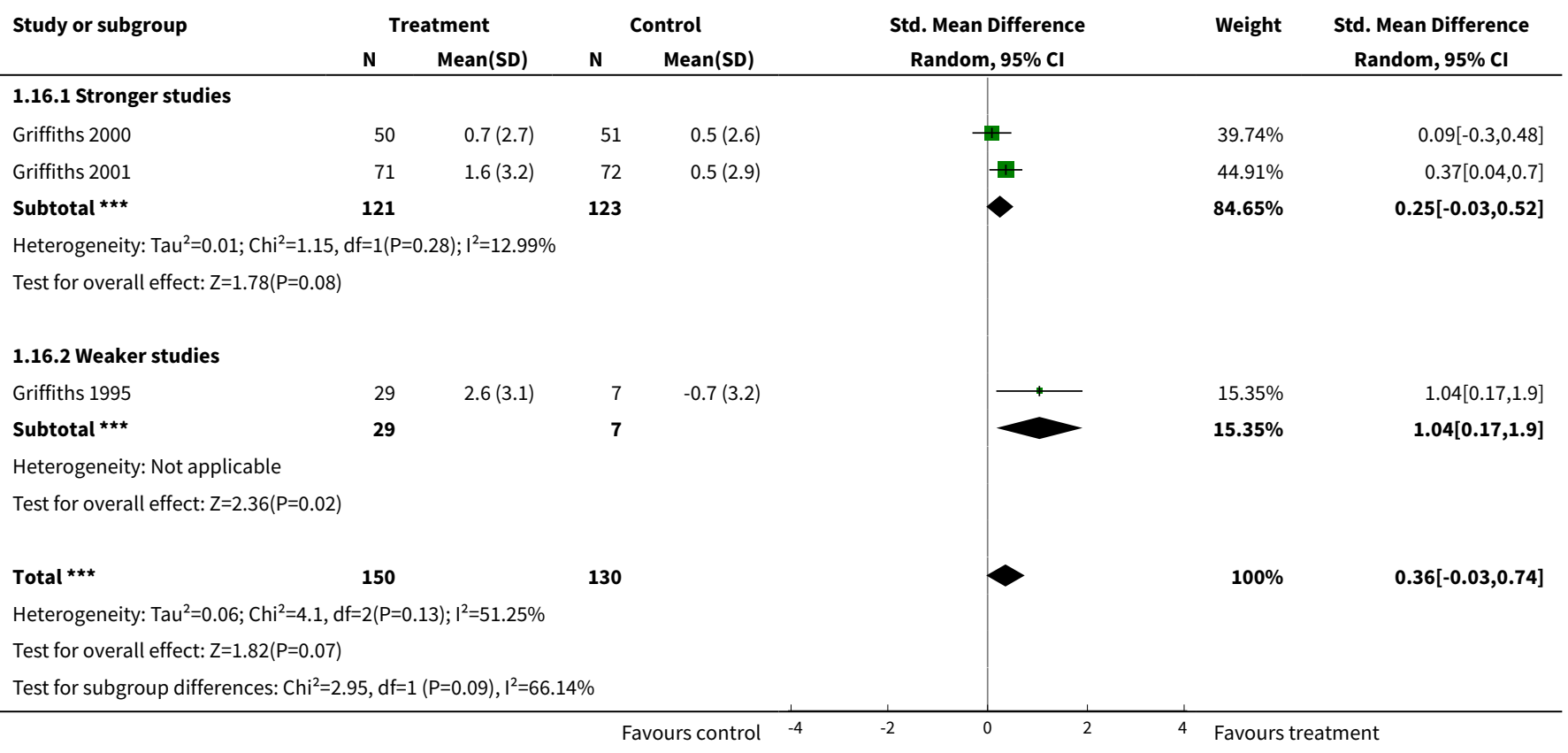

Analysis 1.17. Comparison $1 \mathrm{NLU}$ vs general inpatient care, Outcome 17 Satisfaction.

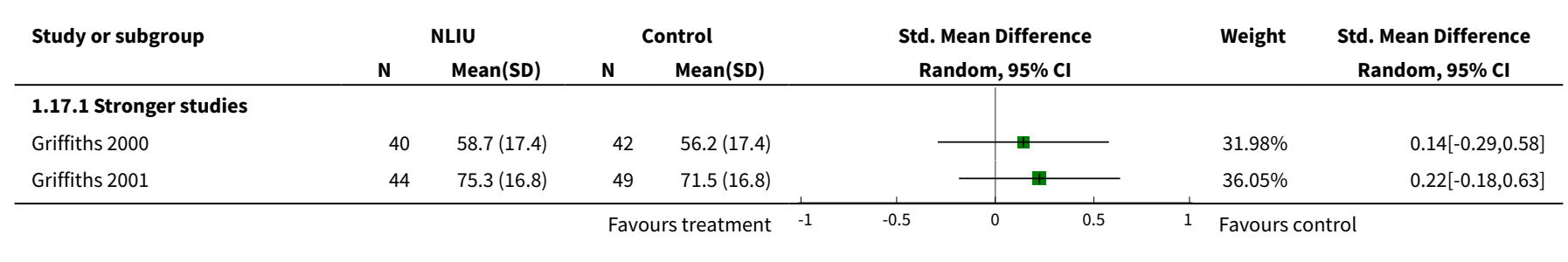




\begin{tabular}{|c|c|c|c|c|c|c|c|}
\hline \multirow[t]{2}{*}{ Study or subgroup } & \multicolumn{2}{|c|}{ NLIU } & \multicolumn{2}{|c|}{ Control } & \multirow{2}{*}{$\begin{array}{c}\text { Std. Mean Difference } \\
\text { Random, } 95 \% \mathrm{Cl}\end{array}$} & \multirow[t]{2}{*}{ Weight } & \multirow{2}{*}{$\begin{array}{c}\text { Std. Mean Difference } \\
\text { Random, } 95 \% \mathrm{Cl}\end{array}$} \\
\hline & $\mathbf{N}$ & $\operatorname{Mean}(S D)$ & $\mathbf{N}$ & $\operatorname{Mean}(S D)$ & & & \\
\hline Subtotal ${ }^{\star \star \star}$ & 84 & & 91 & & & $68.04 \%$ & $0.19[-0.11,0.48]$ \\
\hline \multicolumn{8}{|c|}{ Heterogeneity: $\operatorname{Tau}^{2}=0 ; \mathrm{Chi}^{2}=0.07, \mathrm{df}=1(\mathrm{P}=0.79) ; \mathrm{I}^{2}=0 \%$} \\
\hline \multicolumn{8}{|c|}{ Test for overall effect: $Z=1.22(P=0.22)$} \\
\hline \multicolumn{8}{|c|}{ 1.17.2 Weaker Studies } \\
\hline Pearson 1988a & 45 & $28(0)$ & 25 & $26.6(0)$ & & & Not estimable \\
\hline Pearson 1988b & 58 & $81.5(27.5)$ & 32 & $74.6(13.6)$ & 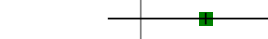 & $31.96 \%$ & $0.29[-0.15,0.72]$ \\
\hline Subtotal $\star \star \star$ & 103 & & 57 & & & $31.96 \%$ & $0.29[-0.15,0.72]$ \\
\hline \multicolumn{8}{|c|}{ Heterogeneity: Not applicable } \\
\hline \multicolumn{8}{|c|}{ Test for overall effect: $Z=1.3(P=0.19)$} \\
\hline Total $\star \star \star ~$ & 187 & & 148 & & & $100 \%$ & $0.22[-0.03,0.46]$ \\
\hline \multicolumn{8}{|c|}{ Heterogeneity: $\mathrm{Tau}^{2}=0 ; \mathrm{Chi}^{2}=0.22, \mathrm{df}=2(\mathrm{P}=0.9) ; \mathrm{I}^{2}=0 \%$} \\
\hline \multicolumn{8}{|c|}{ Test for overall effect: $Z=1.75(P=0.08)$} \\
\hline \multicolumn{8}{|c|}{ Test for subgroup differences: $\mathrm{Chi}^{2}=0.14, \mathrm{df}=1(\mathrm{P}=0.7), \mathrm{I}^{2}=0 \%$} \\
\hline & & & Fav & reatment -1 & -0.5 & 1 Favours & trol \\
\hline
\end{tabular}

\section{Comparison 2. NLU vs ICU}

\begin{tabular}{lllll}
\hline Outcome or subgroup title & $\begin{array}{l}\text { No. of } \\
\text { studies }\end{array}$ & $\begin{array}{l}\text { No. of } \\
\text { partici- } \\
\text { pants }\end{array}$ & Statistical method & Effect size \\
\hline 1 Inpatient mortality & 1 & 220 & Odds Ratio (M-H, Random, 95\% Cl) & $0.62[0.35,1.10]$ \\
\hline $\begin{array}{l}2 \text { Mortality to longest follow up (Up } \\
\text { to } 24 \text { months) }\end{array}$ & 1 & 152 & Odds Ratio (M-H, Random, 95\% Cl) & $0.80[0.40,1.59]$ \\
\hline 3 Discharge to institutional care & 1 & 145 & Odds Ratio (M-H, Random, 95\% Cl) & $0.61[0.30,1.25]$ \\
\hline $\begin{array}{l}4 \text { Length of stay to first discharge } \\
\text { home }\end{array}$ & 1 & 220 & Mean Difference (IV, Random, 95\% Cl) & $-2.0[-10.96,6.96]$ \\
\hline $\begin{array}{l}5 \text { Early readmission (within } 30 \\
\text { days) }\end{array}$ & 1 & 145 & Odds Ratio (M-H, Random, 95\% Cl) & $0.33[0.12,0.94]$ \\
\hline
\end{tabular}

Analysis 2.1. Comparison 2 NLU vs ICU, Outcome 1 Inpatient mortality.

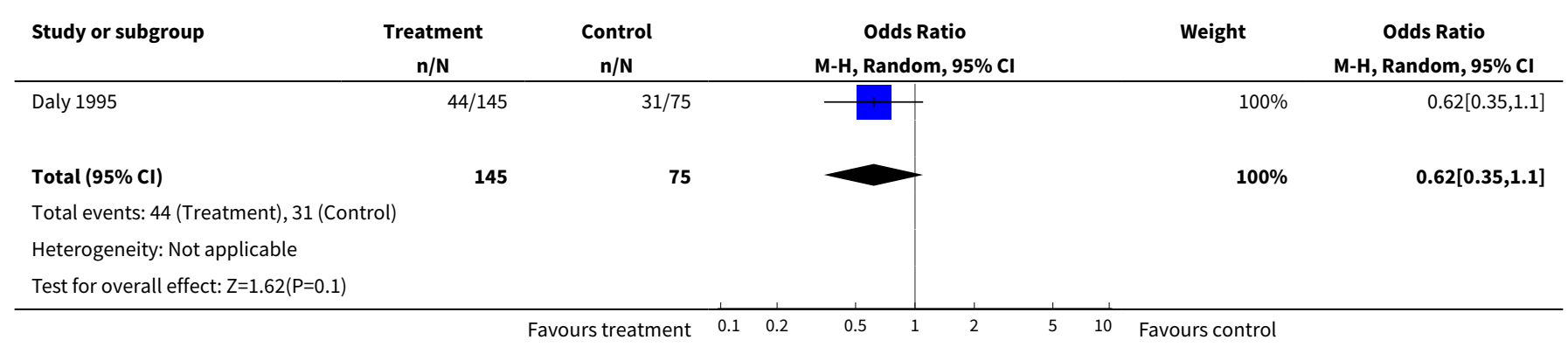


Analysis 2.2. Comparison 2 NLU vs ICU, Outcome 2 Mortality to longest follow up (Up to 24 months).

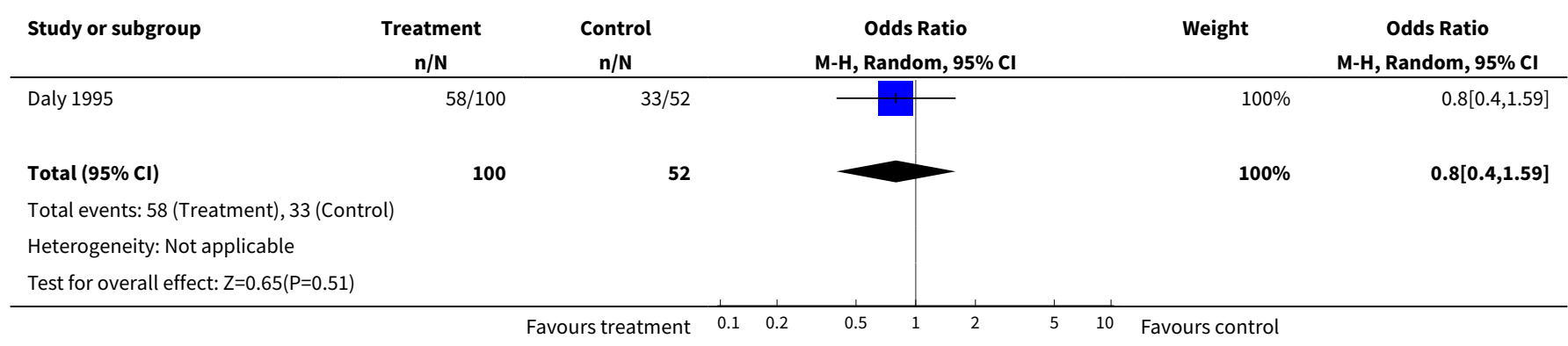

Analysis 2.3. Comparison 2 NLU vs ICU, Outcome 3 Discharge to institutional care.

\begin{tabular}{|c|c|c|c|c|c|}
\hline Study or subgroup & $\begin{array}{c}\text { Treatment } \\
\mathrm{n} / \mathrm{N}\end{array}$ & $\begin{array}{c}\text { Control } \\
\mathrm{n} / \mathrm{N}\end{array}$ & $\begin{array}{c}\text { Odds Ratio } \\
\text { M-H, Random, } 95 \% \mathrm{Cl}\end{array}$ & Weight & $\begin{array}{c}\text { Odds Ratio } \\
\text { M-H, Random, } 95 \% \mathrm{Cl}\end{array}$ \\
\hline Daly 1995 & $45 / 101$ & $25 / 44$ & \begin{tabular}{l|l|l}
1 & & \\
\end{tabular} & $100 \%$ & $0.61[0.3,1.25]$ \\
\hline Total $(95 \% \mathrm{Cl})$ & 101 & 44 & 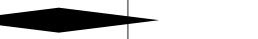 & $100 \%$ & $0.61[0.3,1.25]$ \\
\hline \multicolumn{6}{|c|}{ Total events: 45 (Treatment), 25 (Control) } \\
\hline \multicolumn{6}{|c|}{ Heterogeneity: Not applicable } \\
\hline
\end{tabular}

Analysis 2.4. Comparison $2 \mathrm{NLU}$ vs ICU, Outcome 4 Length of stay to first discharge home.

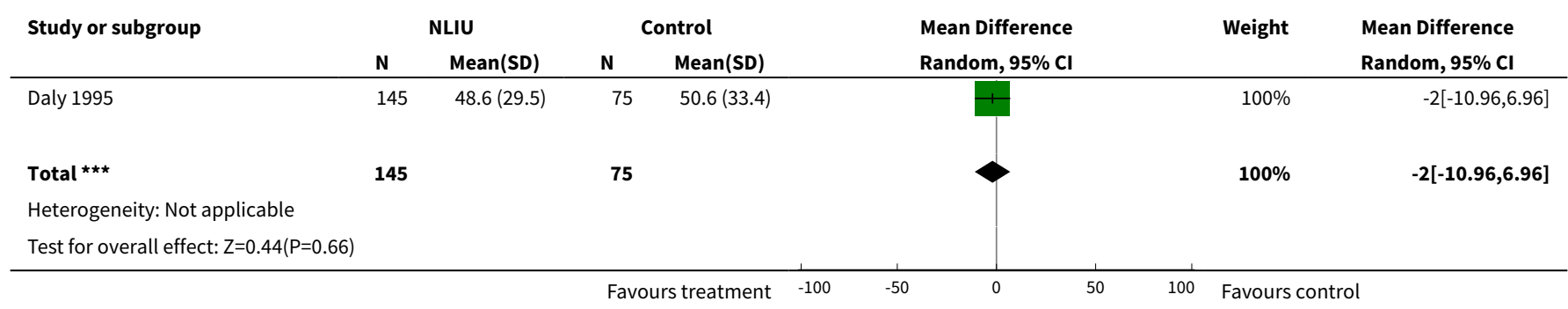

Analysis 2.5. Comparison 2 NLU vs ICU, Outcome 5 Early readmission (within 30 days).

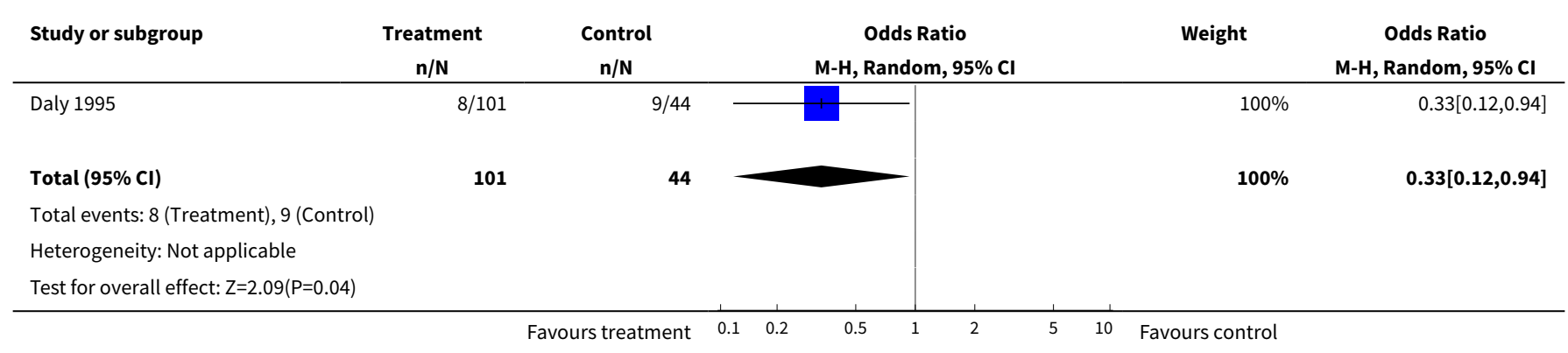


ADDITIONAL TABLES 


\begin{tabular}{|c|c|c|c|c|c|c|c|c|c|}
\hline Study ID & Method & Concealment & Follow Up & $\begin{array}{l}\text { Blinded assess- } \\
\text { ment }\end{array}$ & Baseline & $\begin{array}{l}\text { Reliable as- } \\
\text { sessment }\end{array}$ & $\begin{array}{l}\text { Contamina- } \\
\text { tion }\end{array}$ & $\begin{array}{l}\text { Intention to } \\
\text { treat }\end{array}$ & $\begin{array}{l}\text { Num- } \\
\text { ber (3-7) } \\
\text { 'done' }\end{array}$ \\
\hline Bowcutt 2000 & $\mathrm{RCT}$ & Unclear & Done & * & Unclear & * & Done & Unclear & $2 / 5$ \\
\hline Daly 1995 & $\mathrm{CCT}$ & Not done & Done & Unclear & Done & Done & Done & Unclear & $4 / 7$ \\
\hline Davies 1994 & CBA & & Unclear & & Unclear & Unclear & Unclear & & $0 / 4$ \\
\hline Griffiths 1995 & $\mathrm{RCT}$ & Not done & Done & Not done & Not done & Not done & Done & Done & $3 / 7$ \\
\hline Griffiths 2000 & $\mathrm{RCT}$ & Not done & Done & Not done & Done & Done & Done & Done & $5 / 7$ \\
\hline Griffiths 2001 & $\mathrm{RCT}$ & Done & Done & Not done & Done & Done & Done & Done & $6 / 7$ \\
\hline Hall 1975 & $\mathrm{CCT}$ & Unclear & Done & Not done & Not done & Unclear & Unclear & Done & $2 / 7$ \\
\hline Pearson 1988a & $\mathrm{RCT}$ & Done & Done & Not done & Not done & Unclear & Done & Unclear & $3 / 7$ \\
\hline Pearson 1988b & $\mathrm{RCT}$ & Done & Done & Not done & Not done & Unclear & Done & Not done & $3 / 7$ \\
\hline Steiner 2001 & $\mathrm{RCT}$ & Not done & Done & Unclear & Done & Unclear & Done & Done & $4 / 7$ \\
\hline Walsh 1999 & $\mathrm{RCT}$ & Done & Done & Unclear & Unclear & Unclear & Done & Done & $4 / 7$ \\
\hline
\end{tabular}


Table 2. Costs of care - in-patient

\begin{tabular}{lllll}
\hline Study id & Costs considered & $\begin{array}{l}\text { Treat- } \\
\text { ment cost }\end{array}$ & $\begin{array}{l}\text { Control } \\
\text { cost }\end{array}$ & Notes \\
\hline $\begin{array}{llll}\text { Griffiths } \\
2001\end{array}$ & $\begin{array}{l}\text { In-patient costs to service } \\
\text { providers (from study entry) }\end{array}$ & $\begin{array}{l}£ 5144 \mathrm{per} \\
\text { stay }\end{array}$ & $\begin{array}{l}£ 4100 \mathrm{per} \\
\text { stay }\end{array}$ & $\begin{array}{l}\text { Comprehensive range of resources used identified and } \\
\text { costed directly or estimated. Used a variety of methods to } \\
\text { estimate total inpatient costs (including medical and nurs- } \\
\text { ing care). Cost differences were subjected to a sensitivity } \\
\text { analysis and were not sensitive to assumptions. Main driver } \\
\text { of costs is length of stay. }\end{array}$ \\
& & & &
\end{tabular}

\begin{tabular}{|c|c|c|c|c|}
\hline $\begin{array}{l}\text { Griffiths } \\
2000\end{array}$ & $\begin{array}{l}\text { In-patient costs to service } \\
\text { providers (from study entry) }\end{array}$ & $\begin{array}{l}\text { High es- } \\
\text { timate } £ \\
10,278, \\
\text { Low es- } \\
\text { timate } \\
£ 8,544 \text { per } \\
\text { stay }\end{array}$ & $£ 7,757$ & $\begin{array}{l}\text { Comprehensive range of resources used identified and } \\
\text { costed directly or estimated. Used two methods to esti- } \\
\text { mate cost of medical care for NLU. Magnitude of cost dif- } \\
\text { ference varied depending on this but NLU more expensive. } \\
\text { Main driver of costs is length of stay. }\end{array}$ \\
\hline $\begin{array}{l}\text { Bowcutt } \\
2000\end{array}$ & $\begin{array}{l}\text { Direct hospital costs - un- } \\
\text { specified }\end{array}$ & $\$ 9,445.06$ & $\$ 19 ., 320.87$ & No detail given on costs other than nursing staff \\
\hline $\begin{array}{l}\text { Pearson } \\
1988 a\end{array}$ & $\begin{array}{l}\text { Cost per hospital stay (in- } \\
\text { cluding acute stay) to service } \\
\text { providers }\end{array}$ & $\begin{array}{l}£ 1267.3 \\
\left(£ 1323.6^{\star}\right)\end{array}$ & $£ 1311.9$ & $\begin{array}{l}\text { No detail given on costs other than nursing staff. *Figure in } \\
\text { brackets recalculated from data given in paper. }\end{array}$ \\
\hline $\begin{array}{l}\text { Pearson } \\
1988 b\end{array}$ & $\begin{array}{l}\text { Cost per hospital stay (in- } \\
\text { cluding acute stay) to service } \\
\text { providers }\end{array}$ & $£ 1476.36$ & $£ 1431.42$ & $\begin{array}{l}\text { Costing based on staff cost and average cost per bed (esti- } \\
\text { mated) }\end{array}$ \\
\hline Daly 1995 & $\begin{array}{l}\text { In-patient costs to service } \\
\text { providers (total stay) }\end{array}$ & $\$ 76,077$ & $\$ 81,212$ & $\begin{array}{l}\text { Comprehensive range of resources used identified and } \\
\text { costed directly or estimated.. }\end{array}$ \\
\hline $\begin{array}{l}\text { Steiner } \\
2001\end{array}$ & $\begin{array}{l}\text { In-patient costs to service } \\
\text { providers (from study entry) }\end{array}$ & $£ 7892$ & $£ 4910$ & $\begin{array}{l}\text { Unclear if aggregate daily cost of NLU reflects resources ac- } \\
\text { tually used }\end{array}$ \\
\hline
\end{tabular}

Table 3. Costs of care post discharge

\begin{tabular}{|c|c|c|c|c|}
\hline Study ID & Costs considered & $\begin{array}{l}\text { Treatment } \\
\text { cost }\end{array}$ & $\begin{array}{l}\text { Control } \\
\text { cost }\end{array}$ & Notes \\
\hline $\begin{array}{l}\text { Griffiths } \\
2001\end{array}$ & $\begin{array}{l}\text { Community health and social services } \\
\text { cost and post discharge institutional } \\
\text { charges to public providers }\end{array}$ & $\begin{array}{l}£ 374.91 \text { per } \\
\text { week }\end{array}$ & $\begin{array}{l}£ 401.60 \text { per } \\
\text { week }\end{array}$ & $\begin{array}{l}\text { Comprehensive range of service provider costs } \\
\text { identified. Resource use estimated based on } \\
\text { planned resource use identified in patients dis- } \\
\text { charge plan }\end{array}$ \\
\hline $\begin{array}{l}\text { Griffiths } \\
2000\end{array}$ & $\begin{array}{l}\text { Health and social services cost and } \\
\text { post discharge institutional charges to } \\
\text { public providers in the month after dis- } \\
\text { charge }\end{array}$ & $\begin{array}{l}\text { All costs } \\
£ 990, \text { com- } \\
\text { munity } \\
\text { health and } \\
\text { social ser- } \\
\text { vices only } \\
£ 162\end{array}$ & $\begin{array}{l}\text { All costs } \\
£ 1,259 \text {, } \\
\text { community } \\
\text { health and } \\
\text { social ser- } \\
\text { vices only } \\
£ 253\end{array}$ & $\begin{array}{l}\text { Comprehensive range of service provider costs } \\
\text { identified. Resource use determined direct- } \\
\text { ly from a sample supplemented by estimates } \\
\text { based on planned resource use identified in } \\
\text { patients discharge plan. Total costs include } \\
\text { costs of readmissions }\end{array}$ \\
\hline $\begin{array}{l}\text { Steiner } \\
2001\end{array}$ & $\begin{array}{l}\text { Inpatient and community health ser- } \\
\text { vices cost and post discharge institu- }\end{array}$ & $\begin{array}{l}\text { Total } \\
£ 10,529\end{array}$ & $\begin{array}{l}\text { Total } £ 7819 \\
\text { of which }\end{array}$ & $\begin{array}{l}\text { Comprehensive range of service provider costs } \\
\text { identified over six months from initial entry to }\end{array}$ \\
\hline
\end{tabular}


Table 3. Costs of care post discharge (Continued) tional charges to public providers over six months from entry into the study of which $£ 1879$ post the study. Total costs include costs of readmis$£ 1444$ post discharge sions

WHAT'S NEW

\begin{tabular}{lll}
\hline Date & Event & Description \\
\hline 12 November 2008 & Amended & Changes to format and minor edits. \\
\hline
\end{tabular}

\section{H I S T O RY}

Protocol first published: Issue 3, 2000

Review first published: Issue 4, 2004

\begin{tabular}{lll}
\hline Date & Event & Description \\
\hline 30 July 2008 & Amended & Converted to new review format. \\
\hline 18 January 2007 & $\begin{array}{l}\text { New citation required and conclusions } \\
\text { have changed }\end{array}$ & Substantive amendment \\
\hline
\end{tabular}

\section{CONTRIBUTIONS OF AUTHORS}

PG developed the protocol developed search strategies assessed papers for inclusion abstracted data and drafted the review ME conducted searches assessed papers for inclusion abstracted data and commeneted on drafts of the review AF conducted searches assessed papers for inclusion abstracted data and commeneted on drafts of the review $\mathrm{RH}$ conducted searches assessed papers for inclusion abstracted data and commeneted on drafts of the review GR developed search strategies and conducted searches

\section{DECLARATIONS OF INTEREST}

Peter Griffiths and Ruth Harris have both published studies that were included in this review. Other reviewers considered the methodological quality of these studies.

\section{SOURCES OF SUPPORT}

\section{Internal sources}

- Florence Nightingale School of Nursing and Midwifery at King's College London, UK.

\section{External sources}

- No sources of support supplied

\section{N DEX TERMS}

\section{Medical Subject Headings (MeSH)}

*Intermediate Care Facilities [economics]; *Patient Discharge; *Skilled Nursing Facilities [economics]; Health Care Costs; Hospital Mortality; Length of Stay; Patient Readmission; Randomized Controlled Trials as Topic

\section{MeSH check words}

Humans 